\title{
ОСОБЛИВОСТІ ВПЛИВУ ФУЛЛЕРЕН-ГАЛОГЕНОВОГО СВІТЛА НА ЗАПАЛЬНУ БІЛЬ У ЗАЛЕЖНОСТІ ВІД ХАРАКТЕРИСТИК СВІТЛОВОГО ПОТОКУ
}

\author{
С. О. Ґуляр ${ }^{1,2}$, 3. А. Тамарова ${ }^{1}$ \\ ${ }^{1}$ нститутт фрізіології ім. О. О. Богомольця НАН України \\ ${ }^{2}$ Інтернаціональний медичний інноваційний центр Цептер
}

Вплив перетвореного фуллереном галогенового поляризованого світла на осередок болю або протибольову точку акупунктури викликає анальгетичний есект. Раніше це було доведено нами у тварин на формаліновій моделі болю. В даному дослідженні приділено увагу особливостям анальгетичних реакцій тварин під впливом різних хвильових діапазонів галогенового та фруллеренового світла, виявленню внеску фруллеренового компонента в зниження запального болю залежно від спектру, щільності потужності й освітленості.

Експерименти виконано на мишах із штучно створеним осередком запального соматичного болю (формаліновий тест). Джерелом світла був апарат Bioptron-MedAll, оснащений галогенною лампою. В окремих серіях (усього 80 тварин) досліджували дію на інтенсивність больових і небольових поведінкових реакцій світла, що пройшло крізь фруллеренові фрільтри (на основі CR39 або ПММА) при аплікації його на осередок болю або на точку акупунктури E-36. Анальгетичні ефекти порівнювали з даними, отриманими під дією поліхроматичного (480+ нм і 320+ нм) світла або 3 варіантів плацебо-світла, з урахуванням фрізичних параметрів фрільтрів.

Встановлено, що фруллеренове світло виявилося найбільш анальгетично ефективним незалежно від виду речовини фрільтрів (ПММА або CR39). При аплікації фуллеренового світла (CR39-фрільтр) на осередок болю анальгезія становила 34,3 \%. Виявлена також анальгетична реакція при його дії на точку акупунктури E-36 - 32,6 \%, при цьому галогенне поліхроматичне світло було слабкіше (16,2%). Світло, що пройшло через ПММА-суллереновий фрільтр, при аплікації на осередок болю, послаблювало біль на 29,8 \%. Анальгезія від застосування поліхроматичного світла 480+ нм становила 23,2 \%, а 320+ нм - 14,4 \%. Усі варіанти плацебо-світла були менш ефективні, хоча анальгезія також мала місце: 25,3 \% (CR39 без фруллерена), 24,9 \% (ПММА без фруллерена) та 27,7 \% (фрільтр, що створює спектр, аналогічний фуллереновому). Біологічна ефективність вивчених варіантів світла, оцінена за інтенсивністю больового синдрому, найбільш корелювала з щільністю потужності та хвильовим діапазоном світла. Фуллеренові фрільтри приблизно однаково перетворюють поляризоване світло, з подібним аналгетичним результатом, однак біологічний ефект від CR39-сруллерен світла більш помітний.

Фуллеренове світло в порівнянні з галогеновим має більшу анальгетичну ефективність щодо фрормалін-викликаного болю. Цей результат досягається сорбцією фуллереном частот синьої частини спектра і депресією потужності видимого спектру в цілому.

Ключові слова: поляризоване поліхроматичне світло, апарат Bioptron-MedAll, біль, фрормаліновий тест, анальгезія, фруллерен, фруллерен-модифріковане світло.

\section{PECULIARITIES OF THE FULLERENE-HALOGEN LIGHT INFLUENCE ON INFLAMMATORY PAIN, DEPENDING ON CHARACTERISTICS OF THE LIGHT FLUX}

\author{
S. O. Gulyar ${ }^{1,2}$, Z. A. Tamarova ${ }^{1}$ \\ ${ }^{1}$ Bogomoletz Institute of Physiology, National Academy of Sciences of Ukraine \\ ${ }^{2}$ Zepter International Medical Innovation Center
}

Background. The effect of halogen polarized light transformed by fullerene on the locus of pain or acupuncture analgesic point causes analgesic effect. Earlier this was proved by us in animals on the formalin model of pain. This study focuses on characteristics of analgesic reactions of animals under the influence of different wavelength ranges of halogen and fullerene light and to identify the contribution of fullerene component in reducing inflammatory pain depending on the spectrum, power density and illuminance.

Materials and methods. The experiments were performed on mice with an artificially created locus of inflammatory somatic pain (formalin test). The light source was Bioptron-MedAll device equipped with a halogen lamp. In separate series (80 animals in total) we studied the effect of light transmitted through fullerene filters (based on CR39 or PMMA) on the pain intensity and non-painful behavioral reactions when it was applied to the pain locus or to the acupoint (AP) E-36. Analgesic effects were compared with data obtained under the action of polychromatic (480+ nm and $320+\mathrm{nm})$ light or 3 placebo light options, taking into account physical characteristics of the filters.

Results. It was found that fullerene light gave the best analgesic effect regardless of the type of filter substance (PMMA or CR39). When fullerene light (CR39 filter) was applied to the pain locus, analgesia was $34.3 \%$. An analgesic reaction was also detected during its action on the AP E-36 - 32.6\%, while the halogen polychromatic light was weaker (16.2 \%). The light passing through the fullerene+PMMA filter when applied to the pain locus alleviated pain by $29.8 \%$. Polychromatic light application produced analgesia of $480+\mathrm{nm}$ was $23.2 \%$, and $320+\mathrm{nm}-14.4 \%$. All placebo variants were less effective, although analgesia also occurred: $25.3 \%$ (CR39 fullerene free), $24.9 \%$ (PMMA fullerene free), and $27.7 \%$ (color copy of fullerene filter spectrum). 
Conclusion. The biological effectiveness of the studied light variants, estimated by the intensity of pain syndrome, correlated mostly with the power density and the wavelength range of light. Fullerene filters convert PL almost in the same way, with a similar analgesic result, but the biological effect of fullerene+CR39 light is more noticeable. Fullerene modified light, compared to halogen, has the greatest analgesic efficacy against formalin-induced pain. This result is achieved by the sorption of frequencies of the blue part of the spectrum by fullerene and depression of the power of the visible spectrum as a whole.

Keywords: polarized polychromatic light, Bioptron-MedAll device, pain, formalin test, analgesia, fullerene, fullerene modified light.

\title{
ОСОБЕННОСТИ ВЛИЯНИЯ ФУЛЛЕРЕН-ГАЛОГЕНОВОГО СВЕТА НА ВОСПАЛИТЕЛЬНУЮ БОЛЬ В ЗАВИСИМОСТИ ОТ ХАРАКТЕРИСТИК СВЕТОВОГО ПОТОКА
}

\author{
С. А. Ґуляр ${ }^{1,2}$, 3. А. Тамарова ${ }^{1}$ \\ ${ }^{1}$ Институт фризиологии им. А. А. Богомольца НАН Украины \\ ${ }^{2}$ Интернациональный медицинский инновационный центр Цептер
}

Влияние преобразованного фруллереном галогенового поляризованного света (ПС) на очаг боли или противоболевую точку акупунктуры вызывает анальгетический эфрфект. Ранее это было доказано нами у животных на фрормалиновой модели боли. В данном исследовании уделено внимание особенностям анальгетических реакций животных под влиянием разных волновых диапазонов галогенного и фуллеренового света, выявлению вклада фуллеренового компонента в снижение воспалительной боли в зависимости от спектра, плотности мощности и освещенности.

Эксперименты выполнены на мышах с искусственно созданным очагом воспалительной соматической боли (формалиновый тест). Источником света был аппарат Bioptron-MedAll, оснащенный галогенной лампой. В отдельных сериях (всего 80 животных) исследовали действие на интенсивность болевой и неболевой поведенческих реакций света, прошедшего через фруллереновые фрильтры (на основе CR39 или ПММА) при аппликации его на очаг боли или на точку акупунктуры (TA) E-36. Анальгетические эффекты сравнивали с данными, полученными под действием полихроматического (480+ нм и 320+ нм) света или 3 вариантов плацебо-света, с учетом фризических параметров фрильтров.

Установлено, что фруллереновый свет оказался наиболее анальгетически эффективным независимо от вида вещества фрильтров (PMMA или CR39). При аппликации фруллеренового света (CR39-фрильтр) на очаг боли анальгезия составляла 34.3\%. Выявлена также анальгетическая реакция при его действии на точку акупунктуры E-36 - 32,6 \%, при этом галогенный полихроматический свет был слабее (16,2 \%). Свет, прошедший через РММАфруллереновый фрильтр, при аппликации на очаг боли ослаблял боль на 29,8 \%. Анальгезия от применения полихроматического света 480+ нм составляла 23,2 \%, а 320+ нм - 14,4 \%. Все варианты плацебо-света были менее эфрфективны, хотя анальгезия также имела место: 25,3% (CR39 без фуллерена), 24,9% (ПММА без фуллерена) и 27,7 \% (фильтр, создающий спектр, аналогичный фруллереновому). Биологическая эфрфективность изученных вариантов света, оцененная по интенсивности болевого синдрома, наиболее коррелировала с плотностью мощности и волновым диапазоном света. Фуллереновые фрильтры приблизительно одинаково преобразуют поляризованный свет, с подобным анальгетическим результатом, однако биологический эфреект от CR39-сруллерен света более заметен.

Фуллереновый свет по сравнению с галогеновым обладает большей анальгетической эффективностью по отношению к формалин-вызванной боли. Этот результат достигается сорбцией фуллереном частот синей части спектра и депрессией мощности видимого спектра в целом.

Ключевые слова: поляризованный полихроматический свет, аппарат Bioptron-MedAll, боль, фрормалиновый тест, анальгезия, фруллерен, фруллерен-модифицированный свет. 
Введение. В настоящее время в терапевтической практике успешно используются аппликации низко интенсивного монохроматического лазерного света различных волновых диапазонов от видимого до инфракрасного [1-5]. Однако из-за их спектральной узости не все резонирующие биологические структуры имеют возможность для адекватной реакции. Еще более широкое применение нашли аппараты, излучающие полихроматический поляризованный свет (ПС), среди которых наиболее известны аппараты БИОПТРОН (Швейцария). Исследования этого варианта света показали, что он обладает выраженной биологической активностью, и это его свойство можно успешно применять в лечебной практике [6, 7].

Наши предыдущие исследования на модели воспалительной соматической боли у животных (формалиновый тест) показали, что при аппликации на очаг боли или на точку акупунктуры (ТА) низкоинтенсивный ПС достоверно ослабляет боль [8-16]. При равной экспозиции эффект существенно зависел от волнового диапазона светового излучения. Использование монохроматических фильтров, которые модифицировали полихроматический свет, позволило получить красный, оранжевый, желтый, зелёный, голубой, синий и фиолетовый диапазоны. Для каждого из них экспериментально был установлен факт противоболевого действия ПС, что характеризовало наличие постоянно действующего фактора, независимо от волнового диапазона. С другой стороны, обнаружены дополнительные эффекты, зависящие от физической специфики конкретных диапазонов. Так, «теплые» цвета, в особенности красный, эффективнее подавляют воспалительную болевую реакцию по сравнению с «холодными» $[15,16]$. Наибольший анальгетический эффект оказывал красный свет. Хотя, коротковолновые диапазоны («холодные») оказались более эффективными, как бактерицидные агенты [17].

В последние годы появилось новые материалы, способные на наноуровне изменять свойства проходящего через них света. Среди них особый интерес представляет открытый в конце XX века молекулярный углерод — фуллерен [18]. Одним из свойств материалов, содержащих фуллерен, является способность влиять на световой поток. Это влияние согласно гипотезе Д. Коруги [19] проявляется в изменении направления фотонов от линейно поляризованного до тороидального. Соответственно такой свет получил название
Bioptron ${ }^{\circledR}$ Quantum Hyperlight ${ }^{\circledR}$ (Hyperpolarized light). Наши исследования показали, что ПС, получивший дополнительные свойства при модификации молекулами фуллерена (0,33 \% в ПММА), при действии на очаг боли или на ТА Е-36 достоверно ослабляет боль и оказывает значительное седативное влияние [20, 21]. Кроме этого, при анализе результатов выявлено, что в развитии описанных изменений могут иметь значение изменения в спектре света, прошедшего через слой фуллерена.

Цель работы: изучение особенностей анальгетических реакций животных под влиянием разных волновых диапазонов галогенного и фуллеренового света, выявление вклада фуллеренового компонента в снижение воспалительной боли в зависимости от спектра, плотности мощности, освещенности и технологии создания фильтра.

Материал и методы исследования. Эксперименты выполнены на взрослых белых мышах-самцах массой 27-32 г. Все эксперименты проводились в соответствии с этическими рекомендациями Международной ассоциации боли. Животных содержали в виварии Института физиологии им. А. А. Богомольца НАН Украины, в условиях контролируемой температуры (18-200 С) и 12-часового светового дня. Все животные имели свободный доступ к воде и пище (специальная гранулированная пища). За день до эксперимента мышей помещали в индивидуальные пластиковые клетки и адаптировали к условиям эксперимента. Чтобы уменьшить влияние циркадных ритмов на ноцицептивную чувствительность животных [22], все эксперименты проводились в одно и то же время светлой части дня (с 10 до 13 часов). Каждую мышь использовали только в одном эксперименте, в конце ее усыпляли летальной дозой уретана (внутрибрюшинно).

Экспериментальной моделью для количественной оценки интенсивности дозированной боли был выбран формалиновый тест, который стандартно применяется для определения противоболевой эффективности анальгетиков или физических факторов [23, 24, 25]. Боль создавалась подкожной инъекцией 5 \%-ного раствора формалина (10 мкл/10 г массы тела) в тыльную поверхность стопы левой задней конечности. Очаг воспаления являлся источником боли в течение нескольких часов, но особенно она была заметна в первые 60 минут. Об интенсивности боли судили по частоте и продолжительности циклов лизания больной лапки.

Как известно, реакция на инъекцию формалина состоит их двух фаз $[23,24]$. Первая длится не 
более 10 минут (острая боль) и вторая продолжительная фаза (тоническая боль, обусловленная воспалением в области инъекции). Поскольку в наших экспериментах сразу после инъекции раствора формалина производилась 10-ти минутная аппликация света, во время которой животное находилось в специальной камере, частично ограничивающей его двигательную активность, мы не могли наблюдать первую фазу болевой реакции. В дальнейшем речь будет идти только о второй тонической фазе боли.

Сразу после инъекции раствора формалина в лапку, мышь помещали в цилиндрическую пластиковую камеру с отверстиями для доступа воздуха. Задняя левая лапка, в которую был инъецирован формалин, через специальное отверстие выводилась за пределы камеры и мягко удерживалась на протяжении 10-ти минут рукой экспериментатора. В течение этих 10 минут проводилась аппликация ПС на очаг боли или на противоболевую ТА Е-36. Животное контрольной группы также находилось в камере 10 минут с вытянутой лапкой, но без аппликации света (имитация светового сеанса). Каждая экспериментальная группа содержала 10-12 животных, контрольная группа (плацебо-0) - 20 животных.

Источником непрерывного потока полихроматического галогенного света служил аппарат Bioptron-MedAll, создававший ПС с плотностью мощности $40 \mathrm{MBT} / \mathrm{cm}^{2}$ и выше в зависимости от расстояния. Для уменьшения диаметра светового пятна использовали светонепроницаемую насадку с отверстием 5 мм. Расстояние от стекла светофильтра до поверхности кожи составляло 5 см, непрерывная экспозиция - 10 мин.

Исследовалась (рис. 1) противоболевая эффективность двух вариантов галоген-фуллеренового света в волновом диапазоне 550-3400 (550+) нм: прошедшего через плоский монолитный фильтр, изготовленный из полиметиметакрилата (ПММА), содержащего 0,33 \%о фуллерена, и через вогнутый фильтр, изготовленный из аллильдигликолькарбоната (CR39), на поверхность которого был нанесен фуллерен с защитным слоем. Результаты сравнивали с эффектами полихроматического света с волновым диапазоном от 320 нм (ближний УФ) и 480 нм (без УФ) до 3400 нм. Для понимания роли компонентов, создающих фуллереновый свет, оценивались модификации ПС, созданные при прохождении галогенового света через CR39 и PMMA фильтры, не содержащие фуллерена (плацебо-1 и
2), и плоский фильтр без фуллерена, копирующий спектр фуллеренового фильтра (плацебо-3).

Чтобы выявить зависимость эффективности фуллерен-галогенного света от его физических характеристик были измерены: плотность мощности света, освещенность и волновой диапазон. Для этих целей использовали соответствующую сертифицированную аппаратуру: OPHIR Nova II device (измерения плотности мощности), Lightmeter 401025 (освещенность), spectrometer Solar Laser Systems S-100 и Blu-Wave Vis-25 StellarNet Inc. (волновой диапазон).

Данные обрабатывались статистически. С помощью специальной компьютерной программы рассчитали продолжительность болевых (лизание) и неболевых (сон, умывание, бег, прием пищи) поведенческих реакций для каждых последовательных 10-минутных интервалов времени и для всего периода наблюдения (60 мин). Экспериментальные данные представлены как среднее \pm SEM. Достоверность различий между группами определялась по критерию Стьюдента (t-критерий).

Результаты и их обсуждение. Влияние на соматическую боль галогенного света, прошедшего через фуллерен+CR39 фильтр, при его аппликации на очаг боли или противоболевую TA E-36. Исследования показали, что у животных, которые получали аппликацию фуллеренового+CR39 (550+ нм) ПС на очаг боли или на ТА Е-36, боль была слабее, чем у животных, не получавших сеанса света (рис. 2). Это видно при сравнении кривых, показывающих динамику развития болевого процесса, и суммарных значений. В целом за 60 минут наблюдения после аппликации фуллеренового света болевая реакция была 359,9 с (очаг боли) и 369,3 с (ТА Е-36) против 547,9 с в контроле, что составляет 65,7 \% и 67,4 \% от контрольной величины (табл. 1). Различие статистически достоверно $(\mathrm{p}<0,05)$. Анальгезия составляла 34,3 \% и 32,6 \%.

Действие фуллеренового света (550+ нм) на очаг боли или на противоболевую ТА E-36 не только ослабляло вызванную формалином соматическую болевую реакцию, но также влияло на неболевые поведенческие реакции животных (табл. 1). В группе, получавшей фуллереновый+CR39 ПC, все 4 регистрировавшиеся неболевые реакции отличались от контрольных. Наиболее значимо (в 1,6-2 раза) увеличивалась продолжительность сна (рис. 3), и приема пищи (табл. 1). 
Продолжительность $(\mathrm{M} \pm \mathrm{m})$ болевых и неболевых поведенческих реакций в течение 60 мин наблюдения у контрольных животных (без применения света, $\mathbf{n = 2 0}$ ) и с аппликацией поляризованного света (фуллерен+CR39, 550+ нм) на очаг боли $(\mathrm{n}=10)$ или на TA E-36 $(\mathrm{n}=10)$

\begin{tabular}{|l|c|c|c|c|c|}
\hline \multirow{2}{*}{\multicolumn{1}{|c|}{ Группы, }} & \multicolumn{5}{|c|}{ Длительность болевых и неболевых реакций, с/60 мин } \\
\cline { 2 - 6 } & Боль & Сон & Умывание & Бег & Прием пищи \\
\hline Контроль & $547,9 \pm$ & & & & \\
(плацебо-0 / & 52,0 & $492,3 \pm 100,2$ & $210,2 \pm 26,3$ & $103,4 \pm 26,7$ & $7,6 \pm 4,0$ \\
без света) & $100 \pm$ & $100 \pm 20,4 \%$ & $100 \pm 12,5 \%$ & $100 \pm 25,9 \%$ & (5 из 20) \\
& $9,5 \%$ & & & & \\
\hline & $359,9 \pm$ & $793,1 \pm$ & & & \\
Фуллерен+CR39 & $48,5^{* *}$ & $176,0 *$ & $262,1 \pm 56,0 *$ & $36,5 \pm 6,6 * *$ & $45,8 \pm 2,5^{*}$ \\
(очаг боли) & $65,7 \pm$ & $161,1 \pm$ & $124,7 \pm 11 \%$ & $35,3 \pm 6,4 \%$ & $(2$ из 10$)$ \\
& $8,9 \%$ & $35,7 \%$ & & & \\
\hline & $369,3 \pm$ & $966,7 \pm$ & & & \\
Фуллерен+CR39 & $59,9 * *$ & $211,2 *$ & $186,4 \pm 25,0$ & $82,3 \pm 30,2 *$ & $29,2 \pm 17,6^{*}$ \\
(ТА Е-36) & $67,4 \pm$ & $196,4 \pm$ & $88,7 \pm 11,9 \%$ & $79,6 \pm 29,2 \%$ & $(3$ из 10$)$ \\
& $10,9 \%$ & $42,9 \%$ & & & \\
\hline
\end{tabular}

Примечания: Верхняя строка - продолжительность реакции, с; нижняя - продолжительность реакции, \% от контроля, взятого за 100 \%; в графе «Прием пищи» в скобках указано количество животных, принимавших пищу, от общего количества животных в группе; достоверность различия с контролем: * $<<0,5$; ** $<<0,05$

Таким образом, 10-ти минутная аппликация поляризованного света, модифицированного фильтром фуллерен+CR39, на очаг боли или противоболевую TA E-36 ослабляет индуцированную формалином соматическую боль. Об этом свидетельствует как уменьшение продолжительности болевой реакции, так и увеличение продолжительности сна и приема пищи. При этом результат воздействия на ТА Е-36 фуллереновым светом (CR39) существенно не отличался от анальгетического эффекта, полученного через очаг боли (табл. 1).
Влияние на соматическую боль галогенного света, прошедшего через фуллерен+ПММА фильтр, при его аппликации на очаг боли. Данные, полученные после аппликации на очаг боли ПС, преобразованного фильтром fullerene+PMMA (550+ нм), суммированы в табл. 2 и на рис. 4-5. Для сравнения показаны результаты, полученные в аналогичных условиях у контрольных животных (плацебо-0).

Таблица 2

Продолжительность $(\mathrm{M} \pm \mathrm{m})$ болевых и неболевых поведенческих реакций в течение 60 мин наблюдения у контрольных животных (без применения света, $\mathbf{n = 2 0 )}$ и с аппликацией поляризованного света (фуллерен+ПММА, 550+ нм) на очаг боли $(\mathbf{n = 1 0})$

\begin{tabular}{|l|c|c|c|c|c|}
\hline \multirow{2}{*}{\multicolumn{1}{c|}{ Группы, }} & \multicolumn{5}{|c|}{ Длнна }
\end{tabular}

Примечания: Верхняя строка - продолжительность реакции, с; нижняя - продолжительность реакции, \% от контроля, взятого за 100 \%; в графе «Прием пищи» в скобках указано количество животных, принимавших пищу, от общего количества животных в группе; достоверность различия с контролем: * $<<0,5$; ** $<<0,05$ 
При сравнении средних значений зарегистрированных реакций в группе, где животные получали сеанс поляризованного света, проходящего через фильтр фуллерен+РММА, и в контрольной группе (без применения света), были обнаружены различия для всех поведенческих реакций, кроме бега. Эти группы наиболее заметно отличались по продолжительности боли и сна. Уровень достоверности различий был высоким $(\mathrm{p}<0,05)$. Далее приводим рис. 4-5, иллюстрирующие динамику и общие значения болевых и неболевых реакций в экспериментальной и контрольной группах.

Полученные данные свидетельствуют о значительном снижении интенсивности боли в группе, подвергшейся воздействию поляризованного света, прошедшего через фильтр фуллерен+ПММА, на очаг боли по сравнению с контролем (без применения света). Болевая реакция сократилась в 1,4 раза. В контрольной группе боль составила 547,9 с, а в опытной - на 384,5 с (70,2 \% от контрольной). Уровень достоверности различий составил $\mathrm{p}<0,05$.
Неболевые реакции под воздействием света также изменились. В частности, заметные различия наблюдались в продолжительности сна, которая увеличилась в 2,2 раза. В группе, получавшей световой сеанс с фуллереном, мыши спали в среднем 1076 с против 492,3 с в контрольной группе $(\mathrm{p}<0,05)$. Наиболее выраженные изменения наблюдались во втором 30-минутном периоде наблюдения. Значительно увеличивалась (в 5 раз по сравнению с контрольной группой) продолжительность приема пищи (табл. 2). Увеличение продолжительности сна и приема пищи также указывает на ослабление боли под действием фуллеренового света.

Сравнение анальгетических эффектов фуллеренового света с действием полихроматического света без УФ или галогенового света с УФ. Данные, полученные в условиях применения фуллеренового света (550+ нм), сравнили с результатами после аппликации полихроматического света (480 нм+) и галогенного света без УФ (320+ нм) (табл. 3).

Таблица 3

\section{Длительность $(\mathrm{M} \pm \mathrm{m})$ болевой поведенческой реакции (с и \% от контроля) за 60 мин наблюдения у животных после аппликации на очаг боли или на TA E-36 фуллеренового света (CR39 и ПММА), полихроматического света без УФ и галогенового с УФ в сравнении с контрольной группой (без применения света)}

\begin{tabular}{|l|c|c|}
\hline \multicolumn{1}{|c|}{ Виды света } & Очаг боли & TА Е-36 \\
\hline Фуллерен+СR39 & $359,9 \pm 48,5^{* *}$ & $369,3 \pm 59,9 * *$ \\
$(550+$ nm) & $65,7 \pm 8,9 \%$ & $67,4 \pm 10,9 \%$ \\
\hline Фуллерен+ПММА & $384,5 \pm 34,9^{* *}$ & - \\
$(550+$ nm) & $70,2 \pm 6,4 \%$ & - \\
\hline Полихроматический & $420,7 \pm 69,1^{*}$ & $458,9 \pm 49,8^{*}$ \\
$(480+$ nm) & $76,8 \pm 12,6 \%$ & $83,8 \pm 9,1 \%$ \\
\hline Галогенный & $463,3 \pm 59,6^{*}$ & - \\
$(320+$ nm) & $85,6 \pm 10,9 \%$ & $547,9 \pm 52,0$ \\
\hline Контроль & $547,9 \pm 52,0$ & $100 \pm 9,5 \%$ \\
(плацебо-0 / без света) & $100 \pm 9,5 \%$ & - \\
\hline
\end{tabular}

Примечания: Верхняя строка - продолжительность реакции, с; нижняя - продолжительность реакции, \% от контроля, взятого за $100 \%$; достоверность различия с контролем: * $<<0,5 ;{ }^{* *} \mathrm{p}<0,05$

Из табл. 3 видно, что из всех видов применявшегося света фуллереновый его вариант (как после CR39, так и ПММА фильтра) оказался наиболее эффективным по отношению к подавлению боли. Анальгезия от применения фуллеренового света была большей, чем от полихроматического без УФ и галогенового с УФ света (рис. 6). При аппликации фуллерен+CR39 света на очаг боли анальгезия составляла 34,3\%, а на ТА Е-36 - 32,6 \%. Свет, прохо- дящий через фуллерен+ПММА фильтр (550+ нм), при 10-ти минутной аппликации на очаг боли обеспечивал снижение продолжительности боли на 29,8 \%. Анальгетический эффект от применения полихроматического света (480+ нм) составлял 23,2 \% (очаг боли) и 16,2 \% (ТА Е-36). При этом галогеновый свет без светофильтра (320+ нм) ослаблял боль на 14,4 \% (очаг боли) от контрольной величины, принятой за 100 \%. Следовательно, 
фуллерен усиливал анальгетическое действие поляризованного света.

Влияние на соматическую боль галогенного света, модифицированного плацебо фильтрами, при его аппликации на очаг боли и TA E-36. Чтобы проверить вклад фуллерена в описанный выше эффект подавления боли светом нами проведены эксперименты по аналогичной методической схеме с тремя плацебо фильтрами. Плацебо-1 фильтр был изготовлен из CR39, однако не содержал фуллерена. Плацебо-2 фильтр - из РММА также не содержал фуллерена. Плацебо-3 фильтр также не содержал фуллерена, однако его волновой спектр был аналогичен фуллереновому. Все остальные условия экспериментов и источник света (аппарат Bioptron-MedAll) не отличались от описанных выше.

Влияние на соматическую боль галогенного света, модифицированного CR39-фильтром, не содержащим фуллерена (плацебо-1). Были проведены эксперименты на 10 животных с очагом соматической боли, получивших аппликацию поляризованного света аппарата Bioptron-MedAll, оснащенного фильтром CR39 без фуллеренового покрытия (плацебо-1). Полученные данные сравнивались с аналогичными результатами у животных без воздействия светового излучения (контроль, плацебо-0) и с данными, полученными при использовани света, прошедшего через фильтр CR39 с фуллереновым покрытием (рис. 7, табл. 4).

Было обнаружено, что в группе, где применяемый свет проходил через фильтр плацебо-1 (аппликация на очаг боли), реакция на боль была несколько короче $(409,4$ c), чем в контрольной группе $(547,9$ c).

Уровень значимости различия был очень низкий $(\mathrm{p}<0,5)$. Анальгетический эффект от применения плацебо-1 света составлял 25,3\% (очаг боли)и $13,6 \%$ (ТА Е-36). Как показали наши предыдущие исследования, эффект от применения фуллеренового света, был выше. При аппликации фуллеренового света на очаг боли анальгезия составляла $34,3 \%$, а на ТА E-36 - 32,6 \%.

Таблица 4

Длительность $(\mathrm{M} \pm \mathrm{m})$ болевой и неболевых поведенческих реакций за 60 мин наблюдения у животных с очагом тонической боли, получавших 10-ти минутный сеанс фуллерен+CR39 света на очаг боли и плацебо-1 света в сравнении с контрольной группой (без применения света)

\begin{tabular}{|c|c|c|c|c|c|}
\hline \multirow{2}{*}{ Группы } & \multicolumn{5}{|c|}{ Длительность болевых и неболевых реакций, с/60 мин } \\
\cline { 2 - 6 } & Боль & Сон & Умывание & Бег & Прием пищи \\
\hline Контроль & $384,5 \pm$ & $1076 \pm$ & $178,1 \pm$ & $77,8 \pm$ & $38,3 \pm 35,8^{*}$ \\
(плацебо-0/ & $34,9 * *$ & $220,7^{* *}$ & $30,5^{*}$ & 28,8 & \\
без света) & & & & & \\
\hline СR39 & $409,4 \pm$ & $706,9 \pm$ & $282 \pm$ & $59,7 \pm$ & $19,1 \pm 11,5^{*}$ \\
без фуллерена & $52,3^{*}$ & $195,1^{*}$ & $57,6^{*}$ & $13,2^{*}$ & \\
(плацебо-1) & & & & & $45,8 \pm 42,5^{*}$ \\
\hline Фуллерен & $359,9 \pm$ & $793,1 \pm$ & $262,1 \pm$ & $36,5 \pm$ & \\
+СR39 & $48,5^{* *}$ & $176^{*}$ & $56^{*}$ & $6,6^{* *}$ & \\
\hline
\end{tabular}

Примечания: достоверность различия с контролем: *p<0,5; ** $<<0,05$

Неболевые реакции под действием плацебо-1 света (CR39) в отличие от фуллерен+CR39 света изменялись слабо. Достоверные различия отмечены только по таким реакциям, как сон и бег $(\mathrm{p}<0,5)$. Применение фуллерен+CR39 света с высокой степенью достоверности $(\mathrm{p}<0,05)$ укорачивало болевую реакцию и увеличивало продолжительность сна в 1,6 (очаг боли) и 2 раза (ТА Е-36).

Влияние на соматическую боль галогенного света, модифицированного ПММА фиильтром без фуллерена (плацебо-2). Целью этой серии было установить динамику болевой (лизание очага боли) и неболевых (сон, бег, умывание, питание) поведенческих реакций после воздействия на очаг боли поляризованного света, прошедшего через РММА фильтр, не содержащий фуллерена (плацебо-2), и сравнить результат с эффектом фуллерен+ПММА света. Результаты суммированы в табл. 5 и на рис. 8.

У животных, получавших 10-ти минутную аппликацию ПММА-света, по сравнению с контрольной группой болевая реакция была немного слабее. Однако эти различия только через 50 минут от начала наблюдения достигали высокой степени достоверности $(\mathrm{p}<0,05)$. Суммарные значения длительности 
болевой реакции в контрольной группе $(547,9$ с) и в плацебо-2 группе $(411,7$ c) отличались незначительно $(\mathrm{p}<0,5)$. Анальгезия составляла 24,9\%.

Неболевые реакции в плацебо-2 группе не отличались достоверно от контроля. Продолжительность сна в этой (540,1 с) и контрольной $(492,3$ с) группах практически одинаковы. В противоположность этому, свет, прошедший через РММА фильтр с фуллереном, увеличивал продолжительность сна в 2,2 раза (1076 с). Таким образом, в отличие от фуллерен+РММА света, аппликация на очаг боли плацебо-2 света не меняет существенно как болевую, так и неболевые поведенческие реакции у животных по сравнению с контролем.

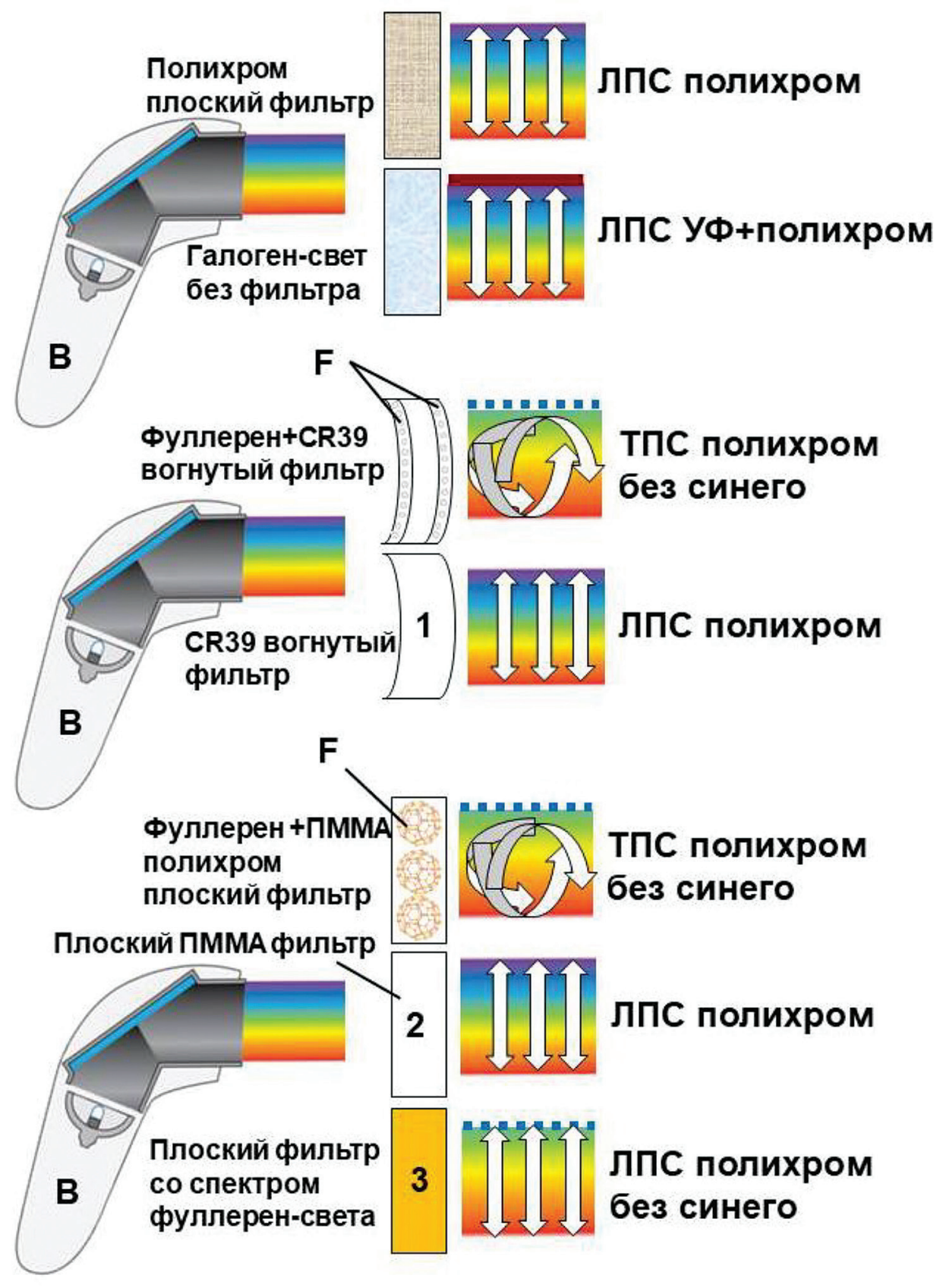

Рис. 1. Особенности фильтров и модификаций поляризованного света: В - аппарат BioptronMedAll с поляризатором Брюстера; F — молекулы фуллерена; ЛПС — линейно поляризованный свет; ТПС - тороидально поляризованный свет; ПММА - полиметилметакрилат; CR39 - аллилдигликолькарбонат; 1 - плацебо-1 (без фуллерена); 2 - плацебо-2 (без фуллерена); 3 - плацебо-3 (безфуллереновый фильтр со спектром фуллеренового света); стрелками показаны направления поляризованных квантовых потоков 


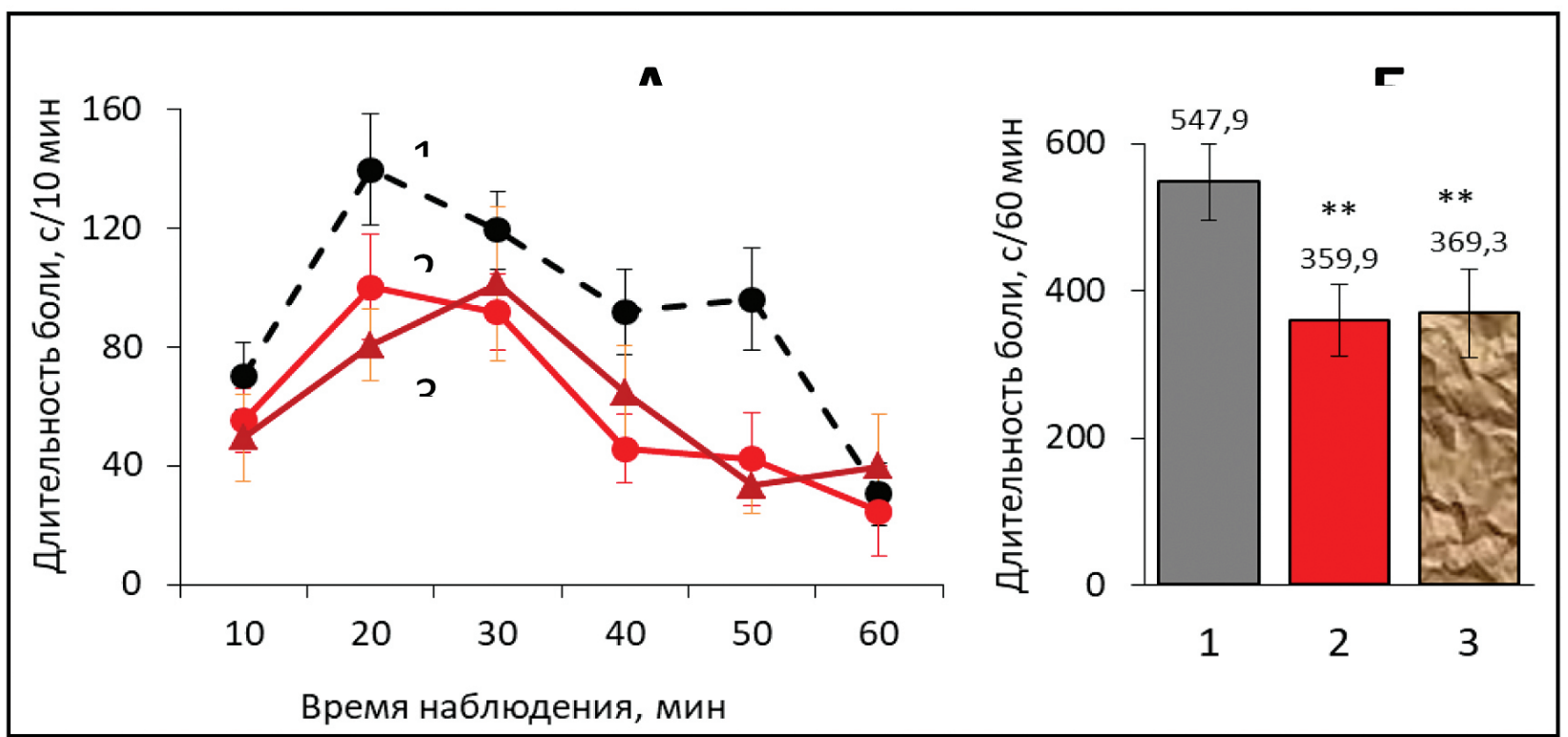

Рис. 2. Динамика (А) и суммарные значения (Б) длительности болевой реакции до и после 10ти минутной аппликации фуллеренового+CR39 (550+ нм) поляризованного света по сравнению с контрольной группой: 1 - контрольная серия (плацебо-0, без применения света); 2 - аппликация фуллеренового света на очаг боли; 3 - аппликация фуллеренового света на точку акупунктуры Е-36. Цифры над столбиками - средняя по группе длительность болевой реакции (с) за 60 мин наблюдения. Достоверность различия с контролем: ** $<<0,05$

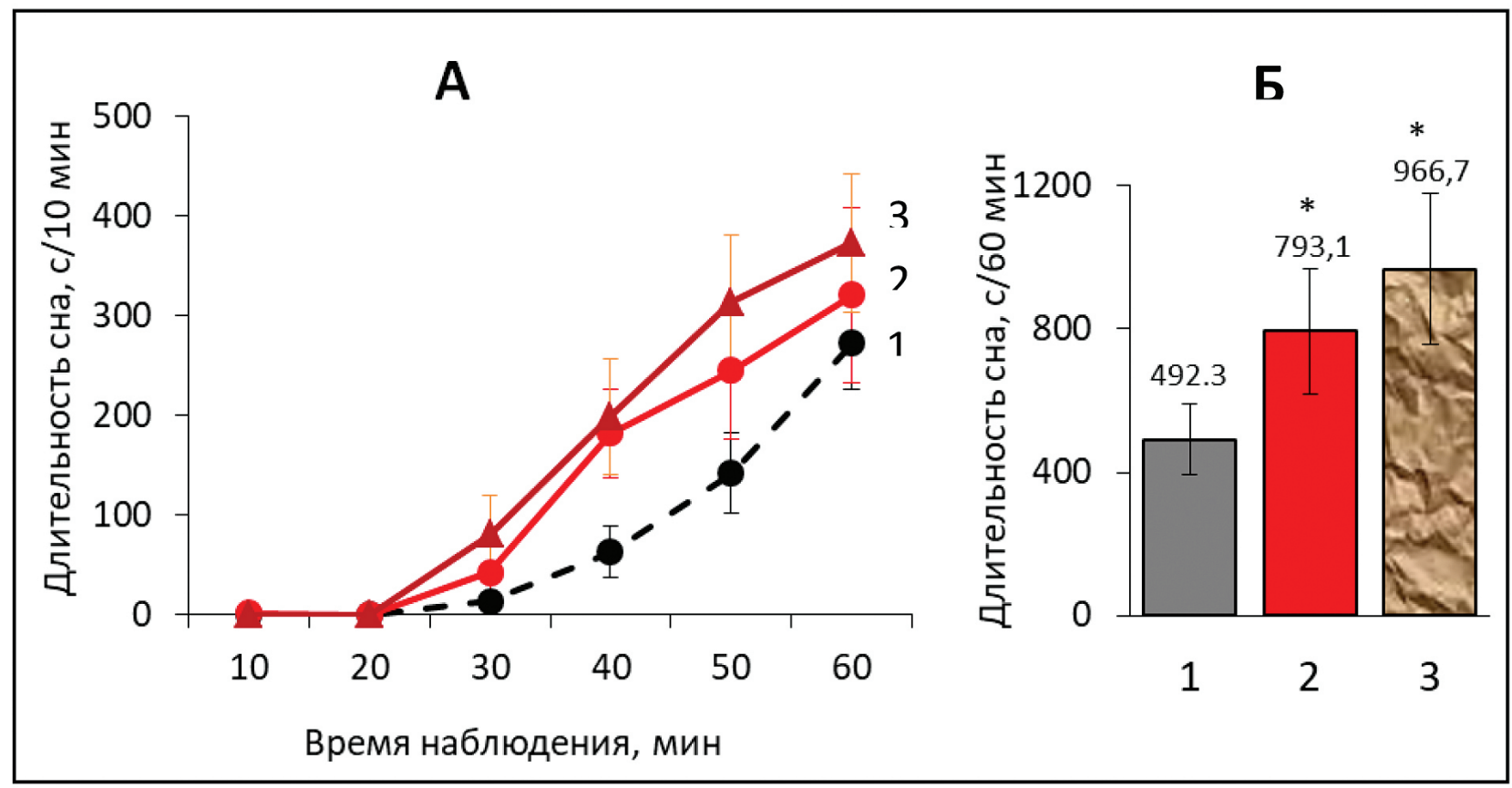

Рис. 3. Динамика (А) и суммарные значения (Б) продолжительности сна до и после 10-ти минутной аппликации фуллеренового+CR39 (550+ нм) поляризованного света по сравнению с контрольной группой: 1 - контрольная серия (плацебо-0, без применения света); 2 - аппликация фуллеренового света на очаг боли; 3 - аппликация фуллеренового света на точку акупунктуры Е-36. Достоверность различия с контролем: * $\mathrm{p}<0,5$ (рис. 2) 


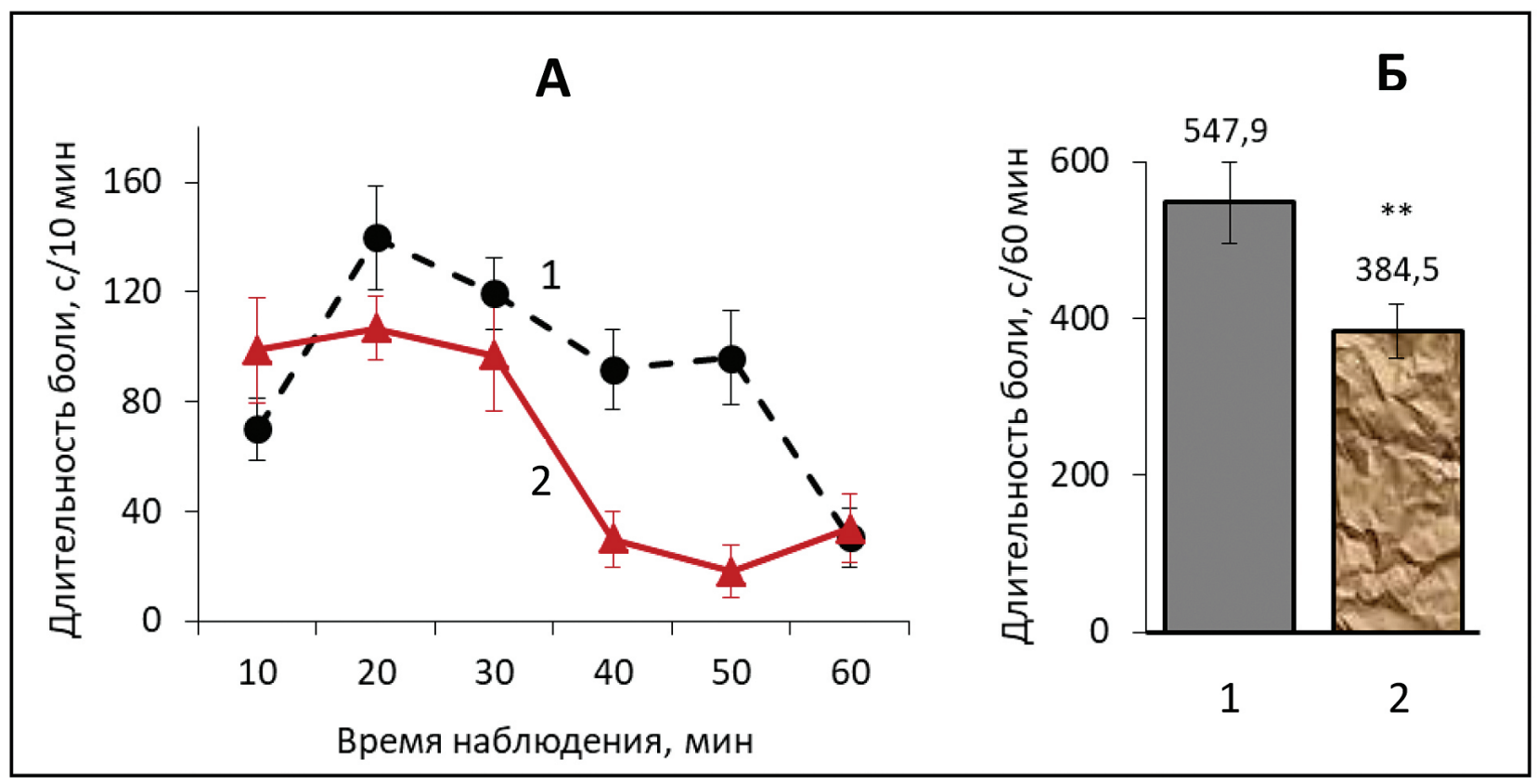

Рис. 4. Динамика (А) и суммарные значения (Б) длительности болевой реакции до и после 10-ти минутной аппликации фуллеренового+ ПММА (550+ нм) поляризованного света по сравнению с контрольной группой: 1 - контрольная серия (плацебо-0, без применения света); 2 - аппликация фуллеренового света на очаг боли. Цифры над столбиками — средняя по группе длительность болевой реакции (с) за 60 мин наблюдения. Достоверность различия с контролем: * $\mathrm{p}<0,5$ (рис. 2)

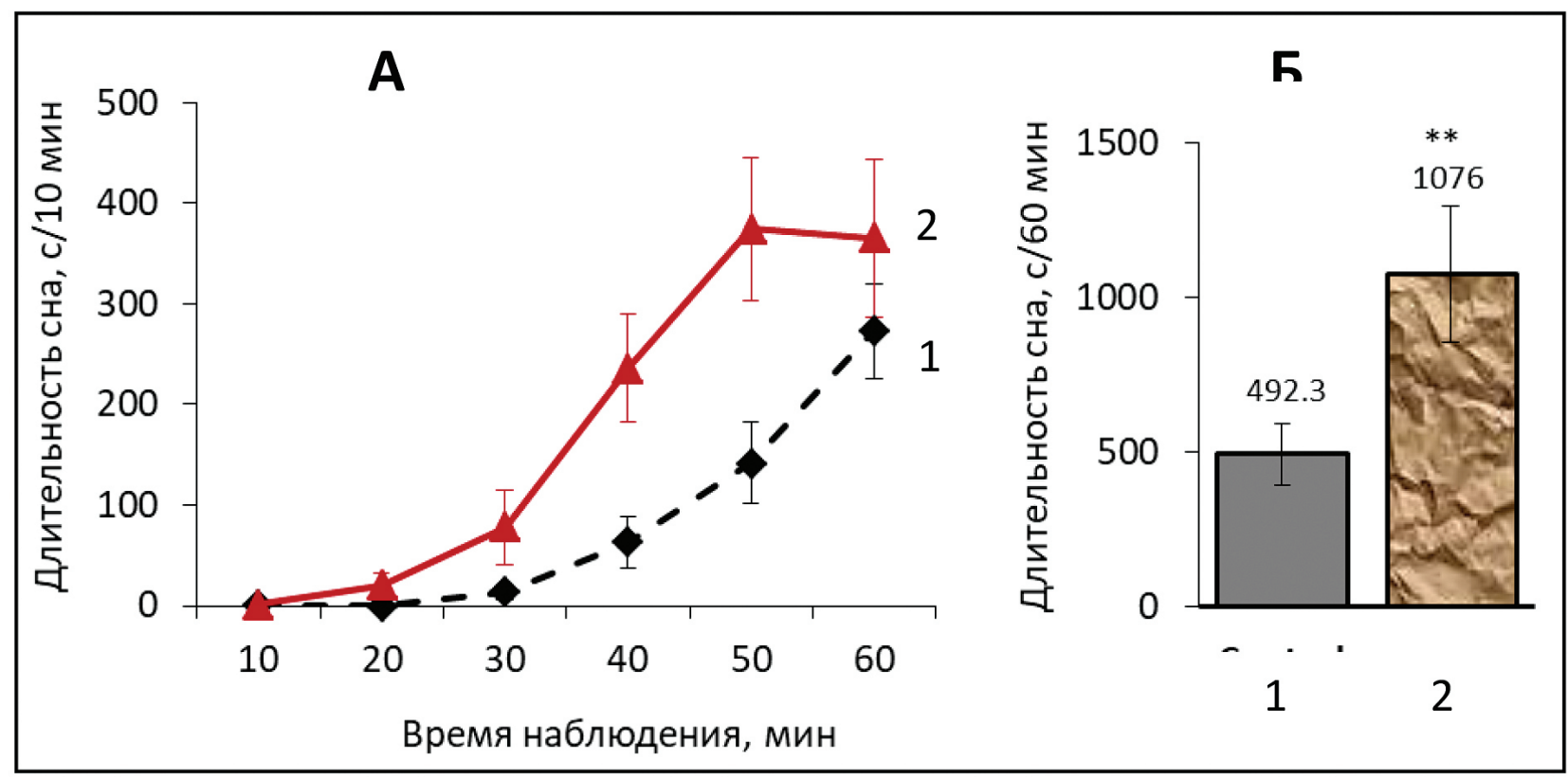

Рис. 5. Динамика (А) и суммарные значения (Б) продолжительности сна до и после 10-ти минутной аппликации фуллеренового+ ПММА (550+ нм) поляризованного света по сравнению с контрольной группой: 1 - контрольная серия (плацебо-0, без применения света); 2 - аппликация фуллеренового света на очаг боли. Достоверность различия с контролем: * $\mathrm{p}<0,5$, ** $\mathrm{p}<0,05 ;$ *** $\mathrm{p}<0,01$ (рис. 2) 

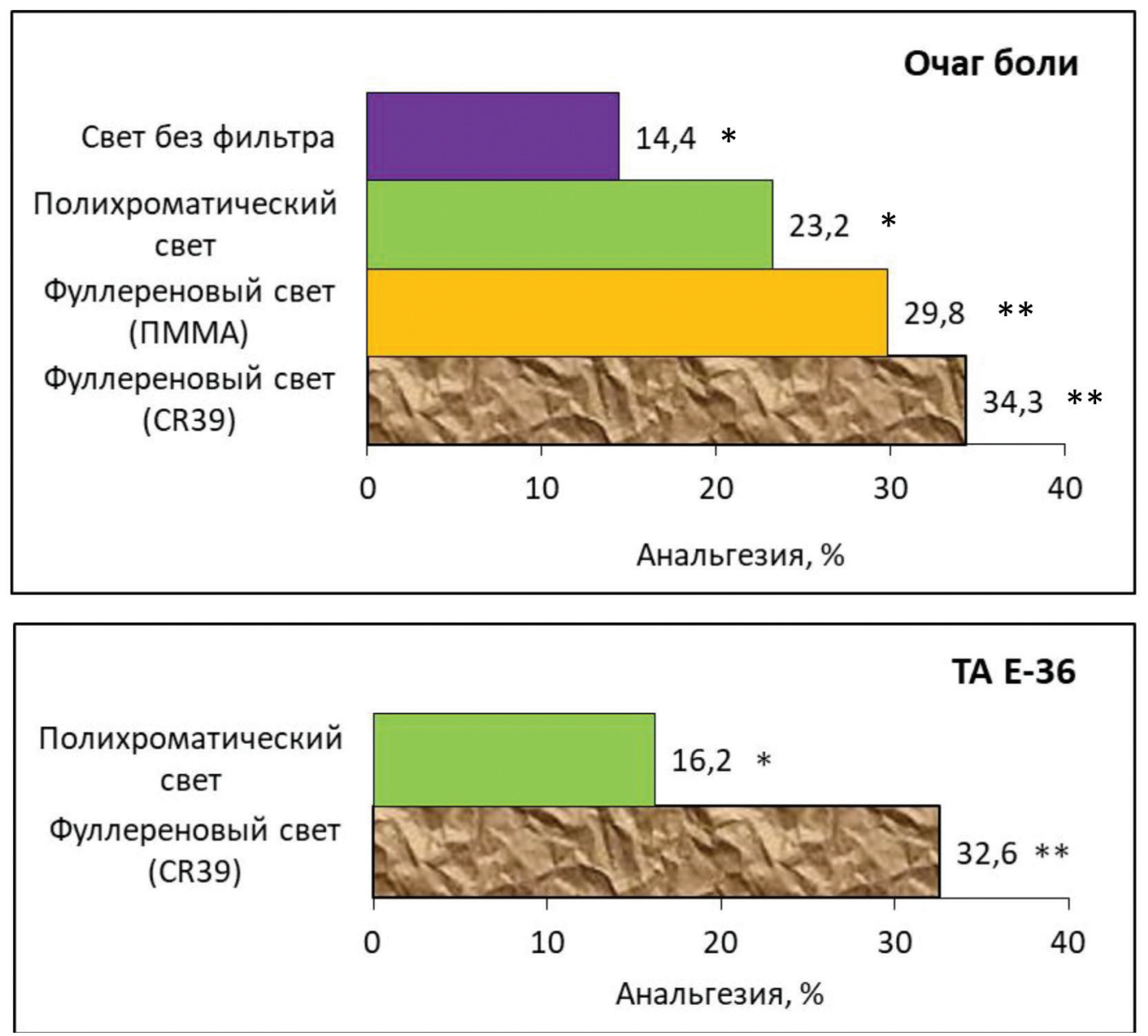

Рис. 6. Сравнение анальгетических эффектов от аппликации на очаг боли и на противоболевую ТА E-36 поляризованного света, модифицированного фуллереновым (CR39 или ПММА 550+ нм) или полихроматическим (480+ нм) фильтрами, а также без фильтра (320+ нм). Достоверность различия с контролем: ${ }^{*} \mathrm{p}<0,5 ; * * \mathrm{p}<0,05$

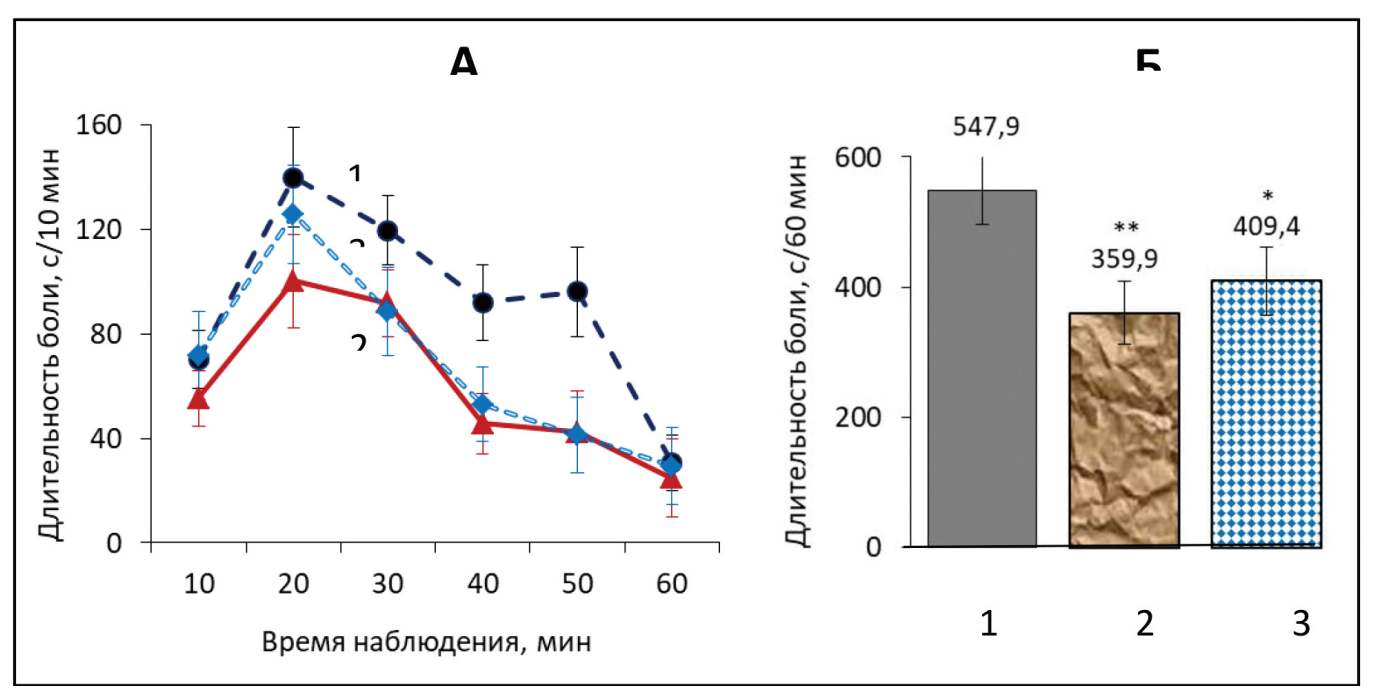

Рис. 7. Динамика (А) и суммарная длительность (Б) болевой реакции после 10 -ти минутной аппликации на очаг боли плацебо-1 света в сравнении с фуллерен+CR39 светом и с контролем: 1 - контрольная серия (плацебо-0, без применения света); 2 - аппликация фуллерен+CR39 света; 3 - аппликация плацебо-1 (CR39 без фуллерена) света. Достоверность различия с контролем: ${ }^{*} \mathrm{p}<0,5 ;{ }^{* *} \mathrm{p}<0,05$ (рис. 2 ) 


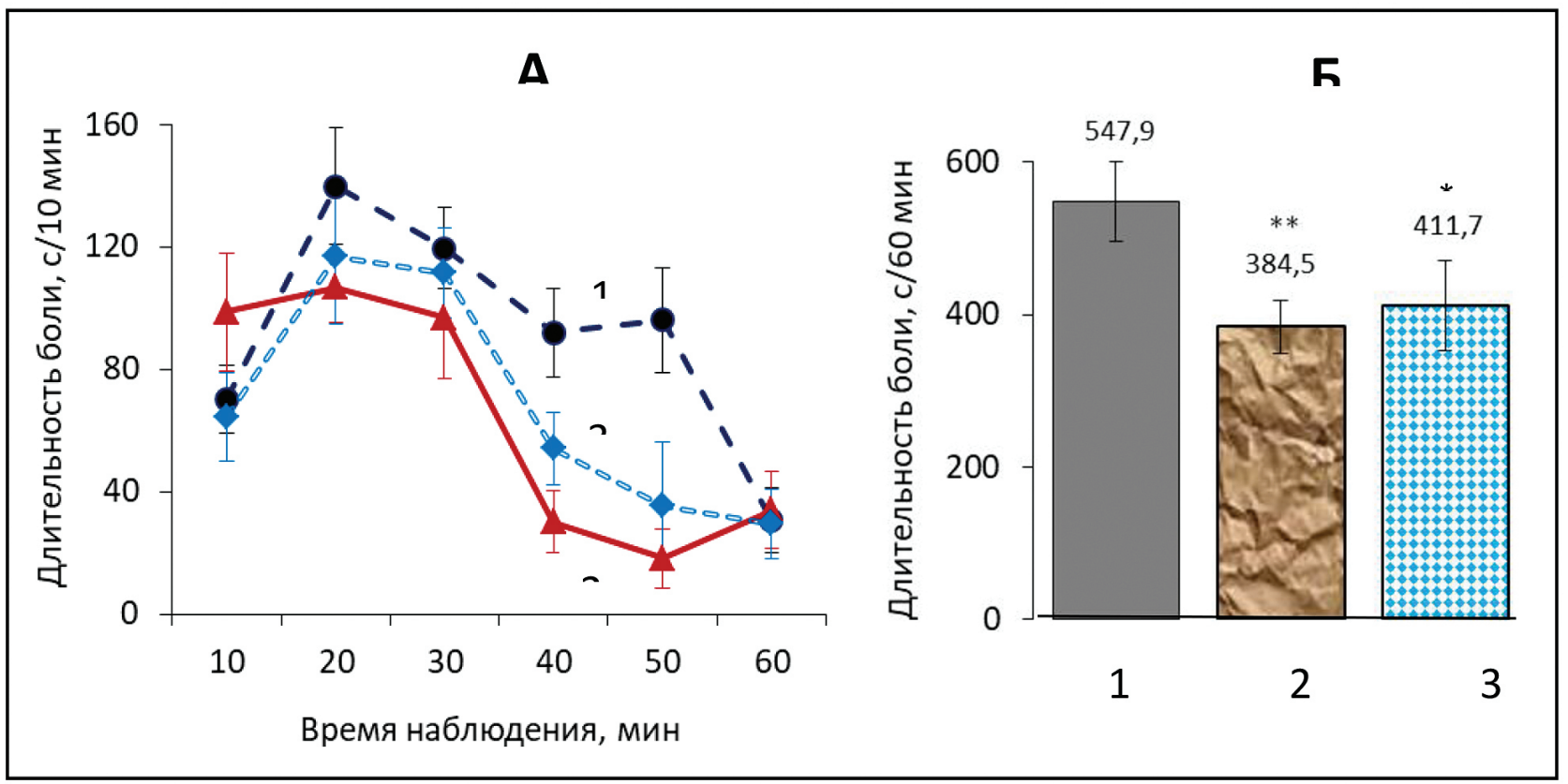

Рис. 8. Динамика (А) и суммарная длительность (Б) болевой реакции после 10-ти минутной аппликации на очаг боли плацебо-2 света в сравнении с фуллерен+РММА светом и с контролем: 1 контрольная серия (плацебо-0, без применения света); 2 - аппликация фуллерен+РММА света; 3 - аппликация плацебо-2 (РММА без фуллерена) света. Достоверность различия с контролем: ${ }^{*} \mathrm{p}<0,5 ; * * \mathrm{p}<0,05$ (рис. 2)

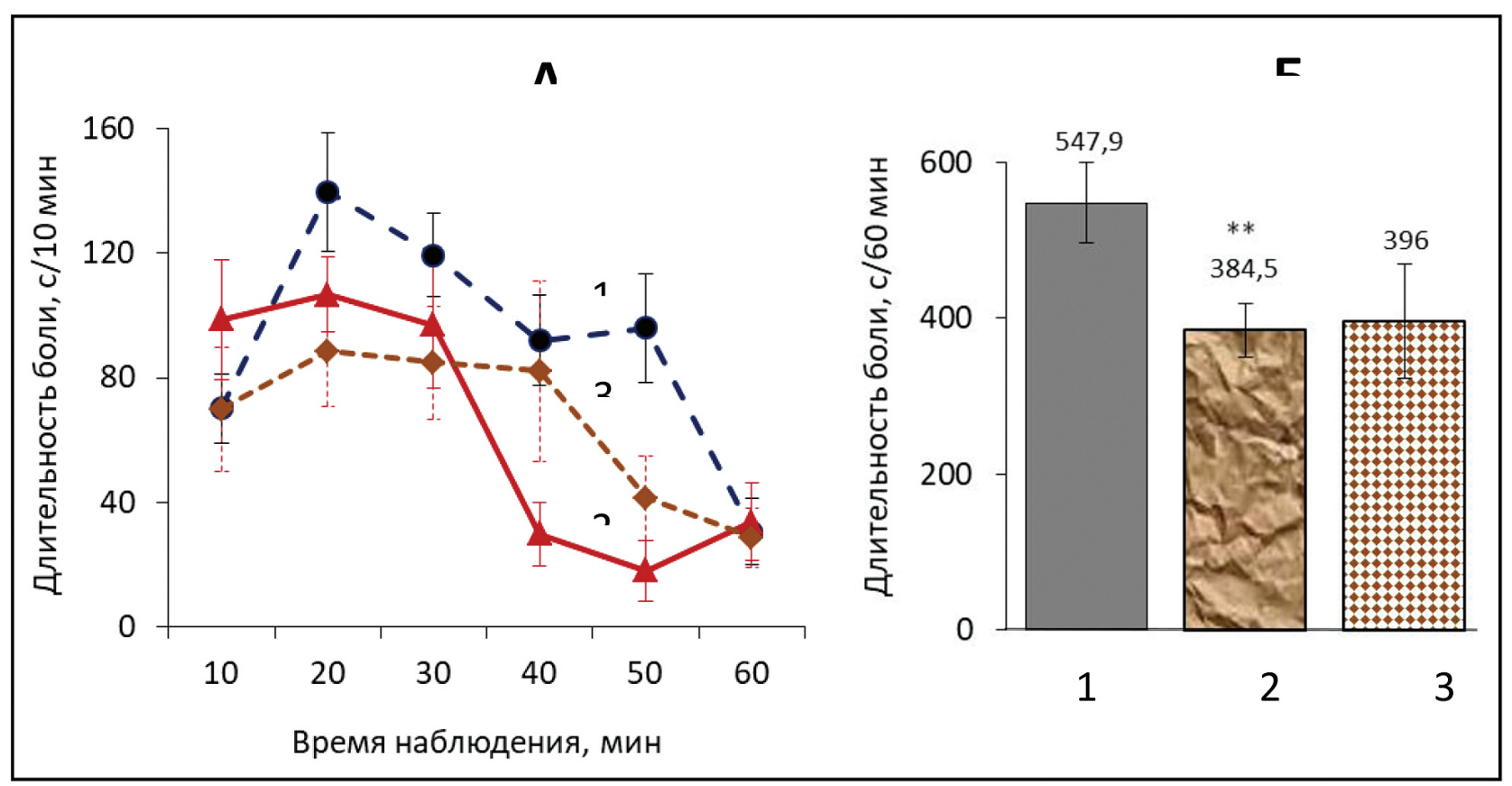

Рис. 9. Динамика (А) и суммарное значение (Б) длительности болевой реакции после 10-ти минутной аппликации на очаг боли плацебо-3 света в сравнении с фуллерен+РММА светом и с контролем: 1 - контрольная серия (плацебо-0, без применения света); 2 - аппликация фуллерен+РММА света; 3 - аппликация плацебо-3 (свет со спектром, аналогичным фуллереновому). Достоверность различия с контролем: ${ }^{*} \mathrm{p}<0,5 ;{ }^{* *} \mathrm{p}<0,05$ (рис. 2) 


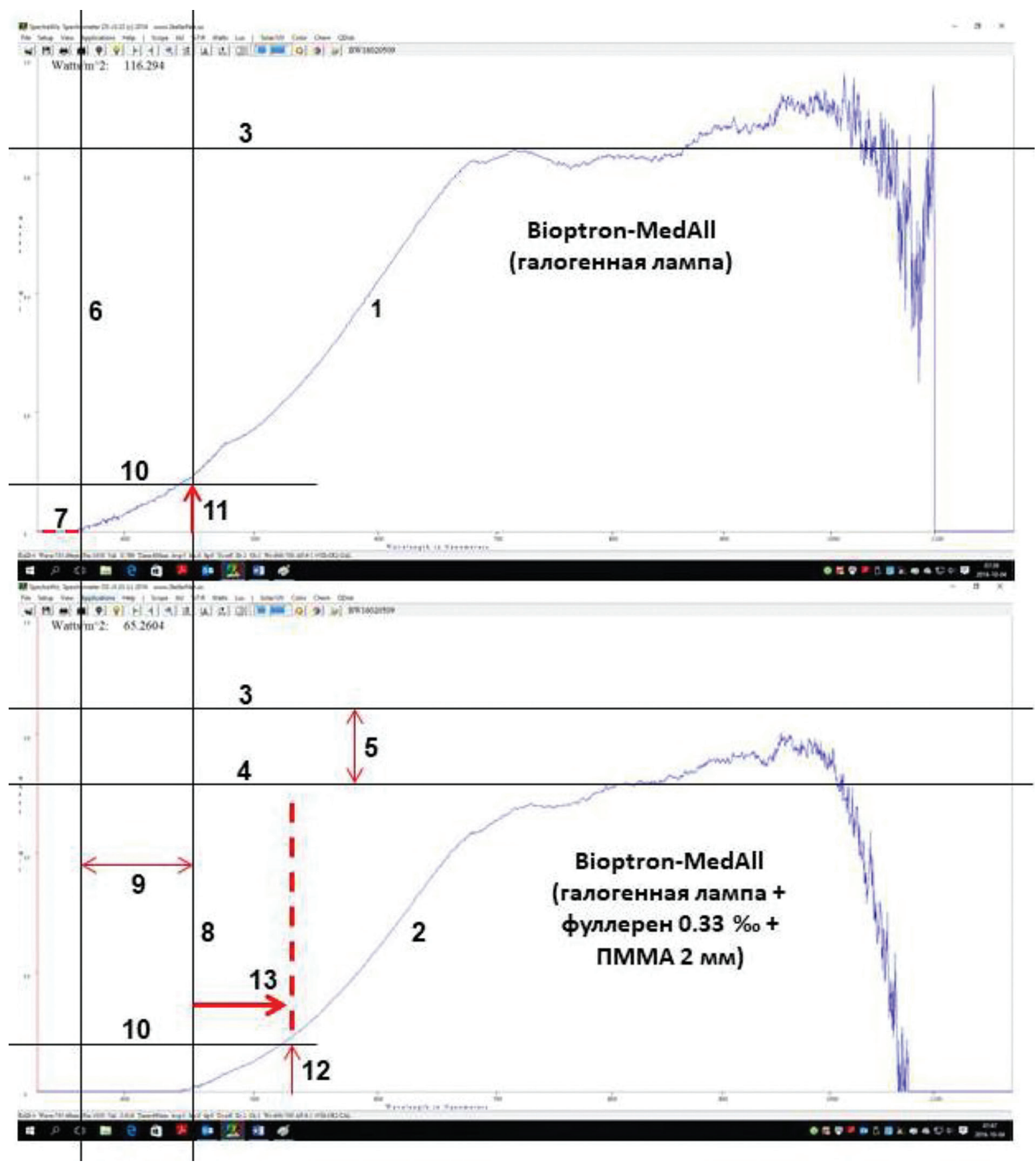

Рис. 10. Сравнение волновых спектров света галогенной лампы аппарата Bioptron-MedAll до и после модификации его фуллереном: 1 - спектр галогенной лампы без светофильтра; 2 - спектр галогенной лампы с фуллереновым+ПММА фильтром; 3 - усредненное плато спектра галогенной лампы; 4 - усредненное плато спектра фуллеренового света; 5 - градиент между усредненными участками спектров; 6 - реперная линия, показывающая начальную точку спектрограммы света галогенной лампы; 7 - точка начала спектра света галогенной лампы (находится за пределами зоны чувствительности spectrometer Blu-Wave Vis-25 Stellar Net Inc); 8 - реперная линия, показывающая начальную точку спектрограммы фуллеренового света; 9 - градиент между начальными точками спектров; 10 - уровень условного порога биологической реакции на свет (20 мВт/см²); 11 - участок спектра, с которого начинается биологическая реакция на галогенный свет; 12 - участок спектра, с которого начинается биологическая реакция на фуллереновый свет; 13 - фуллерен-обусловленное смещение зоны начала биологической реакции. Спектры зарегистрированы спектрометром spectrometer Blu-Wave Vis-25 с диапазоном чувствительности в пределах 300-1000 нм 
Влияние на соматическую боль галогенного света, модифицированного плацебо-3 фильтром, имеющим спектр, аналогичный фуллереновому. В этой серии определялось, имеется ли различие в динамике болевой и неболевых поведенческих реакций после воздействия на очаг боли светом фуллеренового и нефуллеренового происхождения с аналогичным спектральным составом. При сравнении средних значений регистрировавшихся реакций в группе, где животные получали сеанс поляризованного света, проходящего через плацебо-3 фильтр, и в контрольной группе (без применения света), различия обнаружены во всех поведенческих реакциях, кроме умывания. Далее приведены графики (рис. 9), иллюстрирующие динамику и суммарные значения болевых и неболевых реакций в экспериментальной (плацебо-3) и контрольной (плацебо-0/без света) группах, сопоставленные с данными, полученными после действия фуллерен+ПММА светом.

Было обнаружено, что в группе, где свет аппарата Bioptron-MedAll применялся через фильтр плацебо-3 (того же спектра, что и фуллереновый фильтр, но без фуллерена), болевая реакция была несколько короче

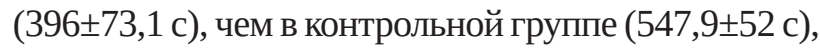
что составило 72,3 \% от контроля. Анальгезия составляла 27,7 \%. Как показали наши предыдущие исследования, под действием света, прошедшего через плоский фуллереновый фильтр, длительность

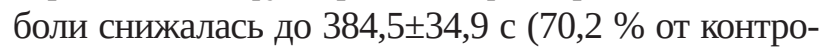
ля). Таким образом, фуллереновый свет был несколько эффективнее, чем свет, прошедший через аналогичный фильтр, но без фуллерена. Однако различие между этими группами статистически не достоверно.

Неболевые реакции под действием плацебо-3 света также изменялись. Продолжительность сна, бега и питания в экспериментальной группе увеличивалась по сравнению с контролем (без применения света). В экспериментальной группе мыши спали в среднем 665,7 с, против 492,3 с в контрольной группе. Продолжительность сна увеличивалась на 35,2 \% от контрольной величины. Мыши были более подвижны. Длительность бега возрастала на 42,4 \% (147,2 с против 103,4 с). Если сравнивать пищевое поведение животных, то в экспериментальной группе принимали корм 50 \% животных (6 из 12), а в контрольной — только $25 \%$ (5 из 20). Увеличение продолжительности сна, бега и питания наряду с сокращением продолжительности болевой реакции, свидетельствует об ослаблении боли под действием света, прошедшего через плацебо-3 фильтр.

Вклад отдельных физических параметров света в его биологическую эффективность. Модификация света различными фильтрами позволяет изолировать отдельные его компоненты и таким образом выявить роль каждого из них (волновой диапазон, плотность мощности, освещенность, поляризация и др.). Разумеется, прочие условия эксперимента должны оставаться без изменений. Именно такой подход применялся нами для реализации поставленной цели исследования.

Величины плотности мощности света аппарата Bioptron-MedAll при идентичном волновом диапазоне фильтров показаны в табл. 5. Различие состояло лишь в наличии или отсутствии фуллерена в материале фильтра. Измерения выявили, что плотность мощности света, проходящего через фуллереновый фильтр и плацебо-3 фильтр, была практически одинаковой (90,9 и 92,4 мВт/см²). Это свидетельствует в пользу близости этих двух фильтров по эффективности (рис. 9). Если пренебречь незначительными различиями из-за того, что объект исследования, хотя и был стандартизованным, но живым (мышь) с индивидуальными вариациями, то можно говорить об идентичности ответной реакции, при близких величинах плотности мощности и волнового диапазона света.

Таблица 5

\section{Плотность мощности света аппарата Bioptron-MedAll в зависимости от свойств фильтра}

\begin{tabular}{|c|c|c|}
\hline Модификатор поляризованного света & $\begin{array}{c}\text { Плотность мощности, } \\
\text { мВт/см }{ }^{2}\end{array}$ & $\begin{array}{c}\text { Коэффициент депрессии } \\
\text { плотности мощности }\end{array}$ \\
\hline Без фильтра & 125,7 & 1,0 \\
\hline Фуллерен (0,33 \%о)+ПММА плоский фильтр & 90,9 & 0,7 \\
\hline $\begin{array}{c}\text { Фильтр, создающий спектр аналогичный } \\
\text { фуллереновому (плацебо-3) }\end{array}$ & 92,4 & 0,7 \\
\hline
\end{tabular}


Анализ этих данных позволил получить дополнительный практический результат: фуллереновый фильтр с концентрацией фуллерена 0,33 \% снижает световую нагрузку на биологические ткани на 28 \%. Этот коэффициент депрессии световой нагрузки можно рассматривать как показатель эффективности светозащитного действия фуллереновых фильтров, которые применяются в настоящее время, с одной стороны, и как фактор, ослабляющий возможный биологический ответ, с другой.

Несмотря на то, что плотность мощности света аппарата Bioptron-MedAll без фильтра была наибольшей по сравнению с фуллереновым или плацебо-3 светом, противоболевое действие в этом случае было наименьшим. Это означает отсутствие прямо пропорциональной зависимости биологического эффекта от мощности света в исследованном диапазоне мощности. Этот результат можно рассматривать с позиции биологического антагонизма красной и синей частей видимого света. «Чистый» свет галогенной лампы имеет расширенный диапазон синей части (от 320 нм и выше), тогда, как диапазон фуллеренового света начинается лишь с 450 нм, а его биологическая эффективность, начиналась с условного порога биологической реакции на свет $\left(20 \mathrm{mBT} / \mathrm{cm}^{2}\right)-$ с 520 нм (рис. 10). Волновое смещение, исходя из спектральных данных, составляло 130 нм, а по биологической эффективности - 70 нм.

Анализ спектров, показанных на рис. 10, выявил градиент между усредненными участками на плато спектрограмм, который стабильно поддерживается на всех волновых частотах. Это значит, что депрессия световой нагрузки, вызванная примесью фуллерена в фильтре, является постоянным фактором.

Также рассмотрено возможное влияние на биологическую эффективность разной освещенности зоны аппликации. Оценивалась освещенность (лк), производимая ПС аппарата Bioptron-MedAll без фильтра, с фуллереновым и с плацебо-З фильтрами. Исследования не выявили прямой зависимости биологического эффекта поляризованного света от освещенности участка кожи (в диапазоне исследуемых величин). Несмотря на то, что свет, прошедший через фуллереновый фильтр, создавал самый низкий коэффициент освещенности $(0,57)$, он оказался самым эффективным. Сравнение болевого ответа на чистый галогеновый свет или свет-имитатор (плацебо-3), которые имели лучшие величины коэффициента освещенности $(1,0$ и 0,84$)$, как было показано выше, не выявило преимуществ таких вариантов света.

Следует отметить, что свет аппарата BioptronMedAll в целом оказывал заметное нагревание поверхности кожи, на которую он был направлен. За 10 минут стандартной экспозиции ее температура повышалась на $8^{\circ} \mathrm{C}$ (с 27 до $35^{\circ} \mathrm{C}$ ). Термический фактор может влиять на биологическую эффективность света. Такая температурная разница может быть полезной с клинической стороны, поскольку создаются лучшие условия для активации микроциркуляции. Однако для физиологического эксперимента она может стать причиной нивелирования различий в эффективности разных фильтров чем, возможно, объясняется низкая достоверность различия между группами в некоторых случаях.

Обсуждение. С появлением нового модификатора света (фуллерена) возникла необходимость уточнения наличия его специфичности в биологическом эффекте. В руки врача или пользователя попадает несколько близких по эффективности вариантов света, например, полихроматический, фуллереновый и др. Поэтому оказался важным сопоставительный анализ эффектов. С одной стороны он расширяет терапевтические возможности светотерапии, с другой позволяет более точно оценить эффективность разных видов светового излучения и провести ранжирование техники.

Наши исследования были направлены на выявление и разграничению вклада очень близких по конечному биологическому эффекту факторов. Применение экспериментальной технологии, стандартизованной не только в рамках данной работы, но и в исследованиях на протяжении предыдущих 20 лет [13, 20, 26, 27] обеспечило нам возможность адекватного сопоставления новых результатов с данными предыдущих исследований, что было необходимым в каждом конкретном случае. Все это повысило уверенность в достоверности результатов.

Если говорить о роли фуллеренового фильтра как модификатора базового галогенного линейно поляризованного света, то можно заметить три вида свойств такого света, которые могут иметь биологической значение. Это элиминация синей части полихроматического спектра, общая депрессия частот на всем волновом диапазоне и эффект переформатирования линейной поляризации 
(гиперполяризация и тороидность) излучения зелено-красной части спектра. Первые два фактора объяснимы из сопоставления спектрограмм. Они имеют экспериментальное подтверждение, в том числе, указывающее на наличие вклада фуллеренового света в биологический ответ. В то же время вопрос о существовании и роли трансформации поляризации света фуллереном еще нуждается в физико-экспериментальном подтверждении. Теоретическая гипотеза выглядят весьма заманчиво [19], однако, благодаря ее представлению лишь на квантовом уровне, получить экспериментальные доказательства роли именно гиперполяризации (поляризационного вклада фуллеренового компонента) на физиологическом и клиническом уровнях пока еще проблематично. На основании современного объема физических непрямых доказательств наличия тороидальной поляризации трудно избавиться от мысли о доминирующей роли фуллерена как сорбента определенных частот и депрессанта мощности всего видимого спектра. В итоге, вынуждены говорить о полиэтиологичности фуллеренового феномена (обозначенного пока пунктирно) к объяснению которого авторы существенно приблизились благодаря применению различных видов плацебо. Однако «молодость» гипотезы и первых окружающих ее данных позволяет надеяться на получение в ближайшем будущем позитивной ее стабилизации в профессиональной среде.

Это не значит, что потребительские свойства фуллереновых фильтров из-за теоретических дискуссий должны страдать. Сейчас можно уверенно говорить о клинической перспективности фуллеренового света, доказанной на болевых моделях и для разных методических схем аппликации [20, 28-30]. Исследования ведутся во многих направлениях, и есть надежда на появление уточняющих или расширяющих современное состояние знаний об оптических, физических и биологических свойствах фуллеренового света. Получены экспериментально-клинические доказательства эффективности фуллереновых фильтров, вмонтированных в очки (Tesla Hyperlight Eyewear® / THE® glasses) [31-34]. Они выявлены при анализе биологической эффективности исходно неполяризованного фуллеренового света, который действовал через окулярный анализатор. Преимущество такого варианта света состояло в активации дефолтных зон и улучшении качества сенсомоторных реакций, выявленных методом электроэнцефалографии. Позитивные изменения под действием фуллеренового света состояли также в улучшении умственной работоспособности (скорость переработки информации, переключение внимания при корректурной работе и др.). Методически в этих исследованиях был достигнут уровень плацебо-1-2, который позволил получить адекватную достоверности результатов.

Описанные выше экспериментальные данные свидетельствуют о наличии противоболевого действия фуллеренового ПС при аппликации его на очаг боли или ТA E-36. Этот эффект заметен как для света, прошедшего через CR39-фильтр (вогнутый фильтр с фуллереновым покрытием), так и через ПММА-фильтр (плоский фильтр, который содержал 0,33 \%о фуллерена). Если сравнить результаты действия разных видов исследованного света, то можно заметить, что анальгезия от применения фуллеренового света была большей, чем от полихроматического (с наличием или отсутствием ближнего УФ диапазона). Так, при аппликации на очаг боли, любой вариант фуллеренового света действовал на боль: после CR39-фильтра он ослаблял боль на 34,3 \%, а после ПММА-фильтра — на 29,8 \%. При тех же условиях полихроматический свет без УФ ослаблял боль на 23,2 \%, а свет с УФ — на 14,4 \% по сравнению с контролем. Следовательно, применение фуллеренового фильтра усиливает анальгетическое действие поляризованного света, созданного аппаратом Bioptron-MedAll. Эти результаты согласуются с полученными ранее на аналогичной модели данными с применением аппарата Bioptron-compact с фуллереновым фильтром [20]. Анальгезия в этом случае составляла 43,5 \% (очаг боли) и 38,5 \% (TA E-36). Понимание общебиологической сопоставимости многих синдромов и патофизиологических механизмов у млекопитающих и результаты наших экспериментов на лабораторных животных дают основание предполагать, что фуллереновые фильтры могут усиливать биологическую эффективность поляризованного полихроматического света и у человека, а также домашних животных.

Заметим, что еще раз получено подтверждение наличия доказанной нами ранее [8, 10, 13, 37] реакции от безконтактного действия света (поляризованного полихроматического, фуллеренового) при его аппликации на очаг воспалительной боли (локальный эффект) и на точку акупунктуры (системный эффект). Точка акупунктуры Е-36 (Цзу-Сан-Ли) считается противоболевой 
с широким спектром дополнительных эффектов, в частности, общетонизирующего, иммунокорректирующего и др. Эти данные, свидетельствуют о том, что фуллерен+CR39 ПС вызывает не только противовоспалительный эффект. Действие на точку акупунктуры Е-36 свидетельствует о возможности получения системной реакции, в данном случае противоболевой [38-39]. Подобные данные были получены нами также и для действия на ТА галогенового поли- и монохроматического света [11, 28-30]. Ранее доказали наличие транспорта электромагнитных сигналов до уровня нейронов центральной нервной системы и активации опиоидэргической антиноцицептивной системы $[25,35]$. Это дает основания клиницистам применять фуллереновую светопунктуру в практике как минимум для ослабления соматической боли. На этом основании были разработаны эффективные схемы коррекции болевых синдромов [27, 29, 30]. Аналогично представляется возможным получение лечебных эффектов и при применении фуллеренового света.

Для понимания роли именно фуллерена, а не комплексов фуллерен+ПММА или фуллерен+CR39, рассмотрим результаты, полученные с фильтрами плацебо (3 варианта).

Два из этих фильтров были изготовлены из материала CR39 или ПММА, но без фуллерена (плацебо-1 и 2), а третий (плацебо-3) - был идентичен фуллерен+ПММА фильтру по волновому спектру. Установлено, что все три плацебо варианта света оказывали биологический эффект, но он был меньшим, чем у фуллеренового света. При аппликации плацебо-1 света на очаг боли анальгезия составляла 25,3 \%, плацебо-2 - 24,9 \% и плацебо-3 - 27,7 \%. Таким образом, было выявлено, что фуллереновый свет создает дополнительное антиноцицептивное действие. Его величина является умеренной, хотя статистически подтвержденной.

Эффективность фуллерен-галогенного света, которую оценивали на основании прямых данных, полученных на модели формалиновой боли, вероятно, будет неодинаковой в зависимости от его физических характеристик. Приведенные данные показали, что противоболевая эффективность света, оцененная по интенсивности болевого синдрома, больше коррелирует с плотностью мощности, чем со значениями освещенности.

Еще большее значение, по-видимому, играет волновой диапазон света. Наибольший биологический эффект вызывает свет, прошедший через фуллереновый фильтр. Другие виды полихроматического света оказывали менее выраженное противоболевое действие. Это относится к диапазонам, начинающимся с 320 и 480 нм. Диапазон фуллеренового света начинается с величин около 550 нм, но порог биологической реакции преодолевается после 600 нм. Это связано с тем, что фуллереновый наполнитель фильтра блокирует синюю часть спектра и снижает плотность мощности по всей спектрограмме в целом. При этом фуллереновый фильтр ослабляет синюю часть спектра в большей степени, чем его основной компонент - ПММА. Такая структура фуллеренового света (зелено-красная) сближает его с диапазоном исследованных нами ранее оранжевого и красного фильтров, произведенных классической стеклодувной технологией. И именно эти диапазоны были наиболее эффективны по отношению к анальгезии [29, 30, 36].

На биологическую эффективность поляризованного света аппарата Bioptron-MedAll может влиять термический фактор. Для него экспериментально определен температурный градиент $8^{\circ} \mathrm{C}$ (с 27 до $35^{\circ} \mathrm{C}$ ), хотя для аппарата Bioptron-compact, оснащенного фуллереновым светофильтром, он составлял 4,60 C [20]. Повышение температуры до $35^{\circ} \mathrm{C}$ не является с биологической точки зрения критичным, т.к. это ниже порога срабатывания болевых рецепторов. Для эффекта термопунктуры также нужны более высокие температуры, необходимо нагреть кожу до $43^{\circ} \mathrm{C}$. Однако при температуре $35^{\circ} \mathrm{C}$ срабатывают неболевые тепловые рецепторы [40], что может привнести вклад в противоболевые эффекты аппарата BioptronMedAll. Средний максимум статического разряда теплого волокна составляет $46^{\circ} \mathrm{C}$ (от 30 до $48^{\circ} \mathrm{C}$ ). Нагрев кожи неизбежно вызывает приток крови к очагу боли, что способствует более быстрому рассасыванию очага воспаления и оказывает обезболивающий эффект. Считаем, что тепловое воздействие на кожу, которое присутствует при всех видах фильтров, нивелирует различие между ними. Вследствие этого, имеем низкий уровень статистического различия между разными экспериментальными группами. Все это свидетельствует о том, что биологический эффект аппарата Bioptron-MedAll во всех описанных выше сериях определялся суммой светового и теплового воздействия. 
Дополнительным фактором, который может влиять на суммарный болеутоляющий результат, также назвали действие микроволнового излучения. Оно было нами ранее обнаружено в излучении аппарата Биоптрон-компакт [41]. Экспериментально доказано, что в спектре поляризованного полихроматического низкоэнергетического излучения с длинами волн 480-3400 нм присутствует микроволновая составляющая. Она находится в диапазоне от 37 до 53 ГГц, т.е. вне видимого света, мощность микроволнового излучения - до 4,6х10-13 Вт/см². Плотность мощности аппарата Bioptron-MedAll выше, чем у аппарата Bioptroncompact, ближе к величинам, зарегистрированным без УФ фильтра. Это значит, что дополнительный биологический эффект исключить было бы необоснованным.

Если проанализировать данные о различиях анальгетических реакций после аппликации поляризованного света, прошедшего через фуллереновые фильтры, на очаг боли (рис. 6), то можно заметить еще одно обстоятельство, на которое пока не акцентировали внимание. Были сопоставлены биологические ответы на стандартный раздражитель в виде дозированной подкожной инъекции раствора формалина в зависимости от структуры фуллеренового фильтра, материал которого (два варианта) возможно мог модифицировать ПС по разному. При этом соблюдалась идентичность практически всех параметров итогового действующего фактора (света): источник ПС, наличие фуллерена, спектральный состав, близкая по величине плотность мощности света, экспозиция, технология эксперимента. Различие состояло лишь в структуре фильтров: плоский монолитный из ПММА, в вещество которого был равномерно импрегнирован порошок фуллерена в концентрации 0,33 \%о (плотность мощности света $90,9 \mathrm{~mW} / \mathrm{cm}^{2}$ с расстояния 5 см), и вогнутый из CR39, на который с двух сторон были нанесены 2 слоя фуллерена с соответствующей защитой от повреждения (86,9 мВт/см² с расстояния 5 см). Оказалось, что наиболее заметный анальгетический эффект создавал ПС, модифицированный вогнутым фильтром фуллерен+CR39. Он ослаблял вызванную формалином болевую/воспалительную реакцию на 34,3 \%, тогда как свет, прошедший через плоский фильтр фуллерен+ПММА - на 29,8 \%. Различие между двумя экспериментальными группами характеризовало устойчивую тенденцию, достоверность которой составляла $\mathrm{p}<0,5$. Это значит, что оба фильтра приблизительно одинаково преобразуют ПС, однако биологический эффект от CR39-фуллерен света более заметен.

Итак, рассмотрены основные варианты фуллеренового света, которые с помощью плацебо объяснили роль практически всех его составляющих за исключением вклада тороидной (гипер) поляризации. Диапазон прироста биоэффекта, возникший за счет модификации поляризованного света фуллереном, оказался практически полностью заполненным. В настоящее время пока не представляется возможным на существующем техническим уровне зарегистрировать наличие тороидной поляризации и распределение квантов в световом потоке, подчиняющееся закону Фибоначчи. Ключевым вопросом, ответ на который является необходимым для дальнейшего применения фуллеренового света с целью повышения его биологического действия, сохраняется получение физических и биофизических доказательств высказанных ранее гипотетических взглядов и выявление физиологических и клинических реакций в ответ на каждый новый биотропный фактор.

Выводы. Полихроматический поляризованный свет аппарата Bioptron-MedAll, прошедший через фуллереновый фильтр (независимо от его основы или структуры - CR39 или ПММА), достоверно ослабляет вызванный формалином болевой ответ. Этот эффект может быть достигнут аппликацией света как на очаг боли, так и на ТА E-36. Анальгезия от применения фуллеренового света проявляется заметнее, чем от полихроматического света без УФ (480+ нм) или с УФА (320+ нм).

При аппликации на очаг боли фуллереновый свет ослаблял воспалительную боль на 34,3 \% (CR39-фильтр) и 29,8 \% (ПММА-фильтр), полихроматический свет - на 23,2 \%, а свет без фильтра — на 14,4 \% по сравнению с контролем. При аппликации плацебо-света на очаг боли анальгезия составляла 25,3 \% (CR39 без фуллерена), 24,9 \% (ПММА без фуллерена) и 27,7 \% (спектр, аналогичный фуллереновому). Таким образом, фуллерен усиливает антиноцицептивное действие ПС, причем более заметная корреляция наблюдалась с плотностью мощности и волновым диапазоном, чем со значениями освещенности. Этот результат достигается сорбцией частот синей части спектра и депрессией мощности видимого спектра в целом. 


\section{Литература.}

1. Effects of Near-Infrared Low-Level Laser Irradiation on Microcirculation / Maegawa Y., Itoh T., Hosokawa T. et al. // Lasers Surg. Med. — 2007. — № 27 (5). P. 427-437.

2. Efficacy of Low Level Laser Therapy in Myofascial Pain Syndrome: An Algometric and Thermographic Evaluation / Hakguder A., Birtane M., Gurcan S. et al. // Lasers Surg. Med. — 2003. — № 33 (5). — P. 339-343.

3. Efficacy of 904 NM Gallium Arsenide Low Level Laser Therapy in the Management of Chronic Myofascial Pain in the Neck: A Double-Blind and Randomize-Controlled Trial / Gur A., Sarac A., Cevik R. et al. // Lasers Surg. Med. — 2004. — № 35 (3). — P. 229-235.

4. Comparison of Laser, Dry Needling, and Placebo Laser Treatments in Myofascial Pain Syndrome / Ilbuldu E., Cakmak A., Disci R., Aydin R. // Photomed. Laser Surg. — 2004. — № 22 (4). — P. 306-311.

5. Effects of $780 \mathrm{~nm}$ Diode Laser Irradiation on Blood Microcirculation: Preliminary Findings on TimeDependent T1-Weighted Contrast-Enhanced Magnetic Resonance Imaging (MRI) / Schaffer M., Bonel H., Spoka R. et al. // J. Photochem. Photobiol. B. - 2000. — № 54 (1). — P. 55-60.

6. Fenyö M. Theoretical and Experimental Basis of Biostimulation / Fenyö M. // Optics Laser Technol. 1984. — № 16. — P. 209-215.

7. BIOPTRON-Analgesia: 10. The Participation of the Opioidergic System in the Analgesic Effect of Polarized Light on the Analgesic Acupuncture Point / Limansky Y., Gulyar S., Tamarova Z. - In Anthology of Light Therapy. Medical Bioptron Technologie. K.: Bogomoletz Institute of Physiology at the National Academy of Sciences of Ukraine, 2009. - P. 266-275.

8. Analgesic effects of Bioptron PILER light / Gulyar S., Limansky Y., Tamarova Z. // J. of Practical Doctor. 1999. — № 4. - P. 21-23.

9. Suppression of Nociceptive Responses in Mice by LowIntensity Microwave Exposure on Acupuncture Points / Limansky Y., Tamarova Z., Bidrov E., Kolbun N. // Neurophysiology. — 1999. — № 31 (4). — P. 290-294.

10. Study of Analgesic Effect of Polarized Light on Acupuncture Points / Limansky Y., Tamarova Z., Gulyar S., Bidrov E. // Fiziol. J. — 2000. — № 46 (6). P. 105-111.

11. Suppression of Visceral Pain by Action of the Low Intensity Polarized Light on Antinociceptive Points of Acupuncture / Limansky Y., Gulyar S., Tamarova Z. // Fiziol. J. — 2003. — № 49 (5). — P. 43-51.

12. Suppression of Pain by Exposure of Acupuncture Points to Polarized Light / Limansky Y., Gulyar S., Tamarova Z. // Pain Res. Manag. — 2006. — № 11 (1). — P. 49-57.

13. Suppression of Pain by Influence of Bioptron-Polarized Lighton Acupoints / Limansky Y., Gulyar S., Tamarova Z. // European J. Pain. — 2006. — № 10. — P. S212.
14. Suppression of Visceral Pain by Exposure of Acupuncture Points to Low-Intensive Polarized Light / Limansky Y., Gulyar S., Tamarova Z. // Abstracts of the 12th World Congresson Pain. August 17-22, 2008. Glasgow, Scotland, UK. — Pres. PT. — P. 338.

15. Antinociceptive Effects of Color Polarized Light in Animal with FormalinTest / Limansky Y., Gulyar S., Tamarova Z. // Fiziol. J. — 2009. — № 55 (3). P. 81-93.

16. BIOPTRON-Analgesia: 12. Role of Color in Tonic Pain Suppression / Limansky Y., Gulyar S., Tamarova Z. In Anthology of Light Therapy. Medical BIOPTRON Technologies. - K.: Bogomoletz Institute of Physiology at the National Academy of Sciences of Ukraine, 2009. - P. 31.

17. Effect of LED radiation of different wavelengths on the growth rate of Staphylococcus aureus / Pantyo V. V., Koval G. M., Pantyo V. I., Gulyar S. A. // ScienceRise: Biological Science. — 2017. — № 7 (4). — P. 16-20; 43-45.

18. The Nobel Prize in Chemistry 1996 / R. F. Curl Jr., H. Kroto, R. E. Smalley // Nobelprize. org. Nobel Media АВ. — 2014. — Web. 31 Aug 2017. — Режим доступа: http://www.nobelprize.org/nobel_prizes/chemistry/ laureates/1996/.

19. Koruga D. Hyperpolarized Light: Fundamentals of Nano Medical Photonics / Koruga D. - Belgrade: Zepter World Book, 2017. — P. 1-306.

20. Modification of Polychromatic Linear Polarized Light by Nanophotonic Fullerene and Graphene Filter Creates a New Therapeutic Opportunities / Gulyar S., Tamarova Z. // Journal of US-China Medical Science. — 2017. — № 14 (5). — P. 173-191.

21. Anti-Pain and Sedative Action of Polychromatic Polarized Light which Passed Through Nanomodification by Carbon Nanofilters / Gulyar S., Tamarova Z. // Proc. of the XLVII International Scientific and Practical Conference Proceedings of Academic Science, Oct. 12-14, 2017, Kyiv. - P. 95-97.

22. Daily Rhythms of Analgesia in Mace: Effects of Age and Photoperiod / Kavaliers M., Hirst M. // Brain Res. — 1983. — № 279 (1-2). — P. 387-393.

23. The Formalin Test: A Quantitative Study of the Analgesic Effects of Morphine, Meperidine and Brain Stem Stimulation in Rats and Cats / Dubuisson D., Dennis S. // Pain. — 1977. — № 4 (2). — P. 161-174.

24. The Formalin Test in Mice: Dissociation between Inflammatory and non-Inflammatory Pain / Hunskaar S., Hole K. // Pain. — 1987. — № 30 (1). — P. 103-114.

25. Involvement of Medullary Opioid Peptidergic and Spinal Noradrenergic Systems in the Regulation of FormalinInduced Persistent Pain / Sugimoto M., Kuraishi Y., Satoh M., Takagi H. // Neuropharmacology. — 1986. - 25 (5). - P. 481-485.

26. Antinociceptive effects of color polarized light in animal formalin test model / Tamarova Z. A., Limansky Yu. 
P., Gulyar S. A. // Fiziol. J. — 2009. — № 55 (3). P. 81-93.

27. Bioptron-PILER-Light Application in Medicine (2nd ed.) / Gulyar S. A., Kosakovskyi A. L., eds. - K.: Bogomoletz Institute of Physiology at the National Academy of Sciences of Ukraine, 2011. — P. 1-256.

28. Comparative evaluation of the analgesic effect of red polarized radiation from halogen and LED sources / Gulyar S., Tamarova Z. // Photobiology and experimental photomedicine. — 2015. — № 12 (1-2). — P. 42-48.

29. Pain and color. Treatment of pain syndromes by polarized light / Gulyar S. A., Tamarova Z. A., Limansky Yu. P. — Kyiv-Donetsk: Biosvet, 2004. — P. 1-122.

30. Pain color therapy. Treatment of pain syndromes by polarized light (2nd Ed) / Gulyar S. A., Tamarova Z. A., Limansky Yu. P. — K.: Ukr. Nat. Acad. Sci, 2007. - P. 1-128.

31. Ocular Influence of Nano-Modified Fullerene Light: 1. Activity of Default Networks of the Human Brain / Gulyar S. A., Filimonova N. B., Makarchuk M. Yu., Kryvdiuk Y. N. // Journal of US-China Medical Science. — 2019. — № 16 (2). — P. 1-15.

32. Ocular Influence of Nano-Modified Fullerene Light: 2. Time correlation of the choice and simple sensorimotor reactions that determine blinding compensation of the driver / Gulyar S. A., Filimonova N. B., Makarchuk M. Yu., Kryvdiuk Y. N. // Journal of US-China Medical Science. — 2019. — № 16 (3). — P. 105-115.

33. Ocular Influence of Nano-Modified Fullerene Light: 3. Speed and Quality of Visual Information Processing in Man / Gulyar S. A., Tamarova Z. A., Kirilenko Ye. K. // Journal of US-China Medical Science. - 2019. № 16 (3). — P. 116-133.

34. Physiological effects of light with spatial structure converted by fullerene / Gulyar S. A., Tamarova Z. A., Kirilenko Ye. K. et al. // Medical Informatics and Engineering. — 2019. — № 45 (1). — P. 39-58.

35. Bioptron-induced analgesia: 10. involvement of opioidergic system in analgetic effect of polarized light on antinociceptive acupuncture point / Limansky Y., Gulyar S., Tamarova Z. - Anthology of light therapy. Medical BIOPTRON technologies. - K.: Bogomoletz Institute of Physiology at the National Academy of Sciences of Ukraine, 2009. - P. 266-275.

36. BIOPTRON-analgesia: 12. Role of color in tonic pain suppression / Limansky Y., Gulyar S., Tamarova Z. — Anthology of light therapy. Medical BIOPTRON technologies. - K.: Bogomoletz Institute of Physiology at the National Academy of Sciences of Ukraine, 2009. - P. 722-731.

37. BIOPTRON-analgesia: 11. Comparative investigation of red polarized light analgesic action while application at pain locus, analgesic acupuncture point and the whole animal / Limansky Y., Gulyar S., Tamarova Z. - Anthology of light therapy. Medical BIOPTRON technologies. - K.: Bogomoletz Institute of Physiology at the National Academy of Sciences of Ukraine, 2009. - P. 716-721.

38. Functional system of the organism electromagnetic balance regulation: mechanisms of primary reception of electromagnetic waves of optical range / Gulyar S., Limansky Y. // Phyziol. J. — 2003. — № 49(2). — P. 35-44.

39. Accents of the Human Body Electromagnetic Balance Regulation System / Gulyar S. A. // Photobiology and Photomedicine. - 2018. — № 24. — P. 52-68.

40. Warm receptors in the nasal region of cats / Hensel H., Kenshalo D. R. // J Physiol. — 1969. — № 204. — P. 99-112.

41. Additional microwave irradiation of Bioptron devices in millimeter range / Tamarova Z. A., Limansky Yu. P., Gulyar S. A. et al. - Anthology of light therapy. Medical BIOPTRON technologies. - K.: Bogomoletz Institute of Physiology at the National Academy of Sciences of Ukraine, 2009. — P. 899-905.

\section{References.}

1. Maegawa, Y., Itoh, T., Hosokawa, T., Yaegashi, K., Nishi, M. (2007). «Effects of Near-Infrared Low-Level Laser Irradiation on Microcirculation. Lasers Surg. Med. 27 (5): 427-37.

2. Hakguder, A., Birtane, M., Gurcan, S., Kokino, S., Turan, F. (2003). Efficacy of Low Level Laser Therapy in Myofascial Pain Syndrome: An Algometric and Thermographic Evaluation. Lasers Surg. Med. 33 (5):339-43.

3. Gur, A., Sarac, A., Cevik, R., Altindag, O., and Sapac, S. (2004). Efficacy of 904 NM Gallium Arsenide Low Level Laser Therapy in the Management of Chronic Myofascial Pain in the Neck: A Double-Blind and RandomizeControlled Trial. Lasers Surg. Med. 35 (3): 229-35.

4. Ilbuldu, E., Cakmak, A., Disci, R., Aydin, R. (2004). Comparison of Laser, Dry Needling, and Placebo Laser Treatments in Myofascial Pain Syndrome. Photomed. Laser Surg. 22 (4): 306-11.

5. Schaffer, M., Bonel, H., Spoka, R., Schaffer, P., Busch, M., Reiser, M., and Dühmke, E. (2000). Effects of 780 nm Diode Laser Irradiation on Blood Microcirculation: Preliminary Findings on Time-Dependent T1-Weighted Contrast-Enhanced Magnetic Resonance Imaging (MRI). J. Photochem. Photobiol. B. 54 (1): 55-60.

6. Fenyö, M. (1984). Theoretical and Experimental Basis of Biostimulation. Optics Laser Technol. 16: 209-15.

7. Limansky, Y., Gulyar, S., Tamarova, Z. (2009). BIOPTRON-Analgesia: 10. The Participation of the Opioidergic System in the Analgesic Effect of Polarized Light on the Analgesic Acupuncture Point. In Anthology of Light Therapy. Medical Bioptron Technologie. Kyiv: Bogomoletz Institute of Physiology at the National Academy of Sciences of Ukraine, 266-75. [In Russian].

8. Gulyar, S., Limansky, Y., Tamarova, Z. (1999). Analgesic effects of Bioptron PILER light. J. of Practical Doctor. (4): 21-3. [In Russian]. 
9. Limansky, Y., Tamarova, Z., Bidrov, E., Kolbun, N. (1999). Suppression of Nociceptive Responses in Mice by Low-Intensity Microwave Exposure on Acupuncture Points. Neurophysiology 31 (4): 290-4. [In Russian].

10. Limansky, Y., Tamarova, Z., Gulyar, S., Bidrov, E. (2000). Study of Analgesic Effect of Polarized Light on Acupuncture Points. Fiziol. J. 46 (6): 105-11. [In Ukrainian].

11. Limansky, Y., Tamarova, Z., Gulyar, S. (2003). Suppression of Visceral Pain by Action of the Low Intensity Polarized Light on Antinociceptive Points of Acupuncture. Fiziol. J. 49 (5): 43-51. [In Ukrainian].

12. Limansky, Y., Tamarova, Z., Gulyar, S. (2006). Suppression of Pain by Exposure of Acupuncture Points to Polarized Light. Pain Res. Manag. 11 (1): 49-57.

13. Gulyar, S., Limansky, Y., Tamarova, Z. (2006). Suppression of Pain by Influence of Bioptron-Polarized Lighton Acupoints. European J. Pain. 10: S212.

14. Limansky, Y., Tamarova, Z., Gulyar, S. (2008). Suppression of Visceral Pain by Exposure of Acupuncture Points to Low-Intensive Polarized Light. Abstracts of the 12th World Congresson Pain. August 17-22. Glasgow, Scotland, UK. Pres. PT 338.

15. Tamarova, Z., Limansky, Y., Gulyar, S. (2009). Antinociceptive Effects of Color Polarized Light in Animal with FormalinTest. Fiziol. J. 55 (3): 81-93. [In Ukrainian].

16. Limansky, Y., Gulyar, S., Tamarova, Z. (2009). BIOPTRON-Analgesia: 12. Role of Color in Tonic Pain Suppression. In Anthology of Light Therapy. Medical BIOPTRON Technologies. Kyiv: Bogomoletz Institute of Physiology at the National Academy of Sciences of Ukraine, 722-31. [In Russian].

17. Pantyo, V. V., Koval, G. M., Pantyo, V. I., Gulyar, S. A. (2017). Effect of LED radiation of different wavelengths on the growth rate of Staphylococcus aureus. ScienceRise: Biological Science, 7 (4): 16-20; 43-45. [In Ukrainian].

18. R. F., Curl Jr., Sir H., Kroto, R. E., Smalley (2014). The Nobel Prize in Chemistry 1996. Nobelprize. org. Nobel Media AB. Web. 31 Aug 2017. Available from: http://www.nobelprize.org/nobel_prizes/chemistry/ laureates/1996/.

19. Koruga, D. (2017). Hyperpolarized Light: Fundamentals of Nano Medical Photonics. Belgrade: Zepter World Book, 1-306. [In Serbian and in English].

20. Gulyar. S., Tamarova, Z. (2017). Modification of Polychromatic Linear Polarized Light by Nanophotonic Fullerene and Graphene Filter Creates a New Therapeutic Opportunities. Journal of US-China Medical Science, 14 (5), 173-191.

21. Gulyar, S., Tamarova, Z. (2017). Anti-Pain and Sedative Action of Polychromatic Polarized Light which Passed Through Nanomodification by Carbon Nanofilters. Proc. of the XLVII International Scientific and Practical Conference Proceedings of Academic Science, Oct. 1214, 2017, Kyiv: 95-97. [In Russian].
22. Kavaliers, M., Hirst, M. (1983). Daily Rhythms of Analgesia in Mace: Effects of Age and Photoperiod. Brain Res. 279 (1-2): 387-93.

23. Dubuisson, D., Dennis, S. (1977). The Formalin Test: A Quantitative Study of the Analgesic Effects of Morphine, Meperidine and Brain Stem Stimulation in Rats and Cats. Pain 4 (2): 161-74.

24. Hunskaar, S., Hole, K. (1987). The Formalin Test in Mice: Dissociation between Inflammatory and nonInflammatory Pain. Pain 30 (1): 103-14.

25. Sugimoto, M., Kuraishi, Y., Satoh, M., Takagi, H. (1986). Involvement of Medullary Opioid Peptidergic and Spinal Noradrenergic Systems in the Regulation of Formalin-Induced Persistent Pain. Neuropharmacology 25 (5): 481-5.

26. Tamarova, Z. A., Limansky, Yu. P., Gulyar, S. A. (2009). Antinociceptive effects of color polarized light in animal formalin test model. Fiziol. J., 55 (3): 81-93.

27. Gulyar, S. A., Kosakovskyi, A. L. eds. (2011). Bioptron-PILER-Light Application in Medicine (2nd ed.). Kyiv: Bogomoletz Institute of Physiology at the National Academy of Sciences of Ukraine, 1-256. [In Russian].

28. Gulyar, S., Tamarova, Z. (2015). Comparative evaluation of the analgesic effect of red polarized radiation from halogen and LED sources Photobiology and experimental photomedicine,12 (1-2): 42-48.

29. Gulyar, S. A., Limansky, Yu. P., Tamarova, Z. A. (2004). Pain and color. Treatment of pain syndromes by polarized light. Kyiv-Donetsk: Biosvet. 1-122. [In Russian].

30. Gulyar, S. A., Limansky, Yu. P., Tamarova, Z. A. (2007). Pain color therapy. Treatment of pain syndromes by polarized light (2nd Ed). Kyiv: Ukr. Nat. Acad. Sci, 1-128. [In Russian].

31. Gulyar, S. A., Filimonova, N. B., Makarchuk, M. Yu., Kryvdiuk, Y. N. (2019). Ocular Influence of Nano-Modified Fullerene Light: 1. Activity of Default Networks of the Human Brain. Journal of US-China Medical Science, 16 (2): 1-15.

32. Gulyar, S. A., Filimonova, N. B., Makarchuk, M. Yu., Krivdiuk, Y. N. (2019). Ocular Influence of NanoModified Fullerene Light: 2. Time correlation of the choice and simple sensorimotor reactions that determine blinding compensation of the driver. Journal of USChina Medical Science, 16 (3): 105-115.

33. Gulyar, S. A., Tamarova, Z. A., Kirilenko, Ye. K. (2019). Ocular Influence of Nano-Modified Fullerene Light: 3. Speed and Quality of Visual Information Processing in Man. Journal of US-China Medical Science, 16 (3): 116-133.

34. Gulyar, S. A., Tamarova, Z. A., Kirilenko, Ye. K., Filimonova, N. B., Makarchuk, N. Yu., Krivdiuk, Yu. N. (2019). Physiological effects of light with spatial structure converted by fullerene. Medical Informatics and Engineering, 45 (1): 39-58. [In Russian]. 
35. Limansky, Y. P., Gulyar, S. A., Tamarova, Z. A. (2009). Bioptron-induced analgesia: 10. involvement of opioidergic system in analgetic effect of polarized light on antinociceptive acupuncture point. Anthology of light therapy. Medical BIOPTRON technologies. Kyiv: Bogomoletz Institute of Physiology at the National Academy of Sciences of Ukraine: 266- 275. [In Russian].

36. Limansky, Y., Gulyar, S., Tamarova, Z. (2009). BIOPTRON-analgesia: 12. Role of color in tonic pain suppression. Anthology of light therapy. Medical BIOPTRON technologies. Kyiv: Bogomoletz Institute of Physiology at the National Academy of Sciences of Ukraine: 722-731. [In Russian].

37. Limansky, Y., Gulyar, S., Tamarova, Z. (2009). BIOPTRON-analgesia: 11. Comparative investigation of red polarized light analgesic action while application at pain locus, analgesic acupuncture point and the whole animal. Anthology of light therapy. Medical BIOPTRON technologies. Kyiv: Bogomoletz Institute of Physiology at the National Academy of Sciences of Ukraine; 716721. [In Russian].

38. Gulyar, S. A., Limansky, Y. P. (2003). Functional system of the organism electromagnetic balance regulation: mechanisms of primary reception of electromagnetic waves of optical range. Phyziol. J., 49 (2): 35-44. [In Ukrainian].

39. Gulyar, S. A. (2018). Accents of the Human Body Electromagnetic Balance Regulation System. Photobiology and Photomedicine, 24: 52-68.

40. Hensel, H., Kenshalo, D. R. (1969). Warm receptors in the nasal region of cats. J Physiol, 204: 99 -112.

41. Tamarova, Z. A., Limansky, Yu. P., Gulyar, S. A., Yanenko, O. P., Kutsenko, V. P., Matsybura, A. P. (2009). Additional microwave irradiation of Bioptron devices in millimeter range. Anthology of light therapy. Medical BIOPTRON technologies. Kyiv: Bogomoletz Institute of Physiology at the National Academy of Sciences of Ukraine, 899-905. [In Russian]. 